\title{
Influence of Silicon Layers on the Growth of ITO and AZO in Silicon Heterojunction Solar Cells
}

\author{
Alexandros Cruz ${ }^{\circledR}$, Florian Ruske, Alberto Eljarrat, Pawel P. Michalowski, Anna B. Morales-Vilches (1), \\ Sebastian Neubert, Er-Chien Wang, Christoph T. Koch ${ }^{\circledR}$, Bernd Szyszka, \\ Rutger Schlatmann (i), and Bernd Stannowski ${ }^{(D)}$
}

\begin{abstract}
In this article, we report on the properties of indium tin oxide (ITO) deposited on thin-film silicon layers designed for the application as carrier selective contacts for silicon heterojunction (SHJ) solar cells. We find that ITO deposited on hydrogenated nanocrystalline silicon (nc-Si:H) layers presents a significant drop on electron mobility $\mu_{\mathrm{e}}$ in comparison to layers deposited on hydrogenated amorphous silicon films (a-Si:H). The nc-Si:H layers are not only found to exhibit a larger crystallinity than a-Si:H, but are also characterized by a considerably increased surface rms roughness. As we can see from transmission electron microscopy, this promotes the growth of smaller and fractured features in the initial stages of ITO growth. Furthermore, secondary ion mass spectrometry profiles show different penetration depths of hydrogen from the thin film silicon layers into the ITO, which might both influence ITO and device passivation properties. Comparing ITO to aluminum doped zinc oxide (AZO), we find that AZO can actually exhibit superior properties on nc-Si:H layers. We assess the impact of the modified ITO $R_{\mathrm{sh}}$ on the series resistance $R_{s}$ of SHJ solar cells with $>23 \%$ efficiency for optimized devices. This behavior should be considered when designing solar cells with amorphous or nanocrystalline layers as carrier selective contacts.
\end{abstract}

Index Terms-Aluminum doped zinc oxide (AZO), indium tin oxide (ITO), secondary ion mass spectrometry (SIMS), series resistance, silicon heterojunction (SHJ), transmission electron microscopy (TEM), transparent conductive oxide (TCO).

Manuscript received August 29, 2019; revised November 1, 2019; accepted November 22, 2019. This work was supported in part by the German Ministry of Economic Affairs and Energy (BMWi) in the framework of the Dynasto (0324293B) and ProSelect (0324189C) projects. (Corresponding author: Alexandros Cruz.)

A. Cruz, A. B. Morales-Vilches, S. Neubert, E.-C. Wang, R. Schlatmann, and B. Stannowski are with the PVcomB, Helmholtz-Zentrum Berlin fur Materialien und Energie GmbH, 12489 Berlin, Germany (e-mail: alexandros.cruz@helmholtz-berlin.de; ana.morales_vilches@helmholtz-berlin. de; sebastian.neubert@helmholtz-berlin.de; er-chien.wang@helmholtz-berlin. de; rutger.schlatmann@helmholtz-berlin.de; bernd.stannowski@helmholtzberlin.de).

F. Ruske is with the Institute for Silicon Photovoltaics, Helmholtz-Zentrum Berlin fur Materialien und Energie GmbH, 14109 Berlin, Germany (e-mail: florian.ruske@helmholtz-berlin.de).

A. Eljarrat and C. T. Koch are with the Department of Physics, HumboldtUniversitat zu Berlin, 14109 Berlin, Germany (e-mail: aeljarrat@physik.huberlin.de; christoph.koch@hu-berlin.de).

P. P. Michalowski is with the Institute of Electronic Materials Technology, 01-919 Warszawa, Poland (e-mail: pawel.michalowski@itme.edu.pl).

B. Szyszka is with the Institute of High-Frequency and Semiconductor System Technologies, Technische Universitat Berlin, 10623 Berlin, Germany (e-mail: bernd.szyszka@tu-berlin.de).

Color versions of one or more of the figures in this article are available online at http://ieeexplore.ieee.org.

Digital Object Identifier 10.1109/JPHOTOV.2019.2957665

\section{INTRODUCTION}

$\mathbf{S}$ ILICON heterojunction (SHJ) solar cell technology is positioned as a strong candidate for mass production due to its high-efficiency potential and the lean manufacturing process consisting of only four main steps [1]. Record single-junction efficiencies for crystalline silicon (c-Si) based lab solar cells of $25.1 \%$ and $26.7 \%$ for two-side and all-back contacted devices, respectively, make this cell concept very attractive [2]-[4]. Recently, efficiencies above $24 \%$ have been reported for full-size SHJ solar cells processed on mass production systems [5], [6]. This solar cell concept achieves high open-circuit voltages $\left(V_{\mathrm{oc}}\right)$ above $740 \mathrm{mV}$ through passivating selective contacts. Typically, a thin $(3-5 \mathrm{~nm})$ intrinsic hydrogenated amorphous silicon [(i)a-Si:H] layer is deposited for surface passivation on both sides of the silicon wafer followed by p-doped and n-doped a-Si:H layers that act as carrier selective contacts for holes and electrons, respectively [7]. In recent years, hydrogenated nanocrystalline silicon (nc-Si:H) layers have been implemented as more conductive and transparent selective contact alternatives [8]-[12]. The lateral conductivity of such layers (and the $\mathrm{Si}$ bulk) is relatively low and a transparent conductive oxide (TCO) is needed to achieve a sufficiently low resistive lateral carrier transport to the metal-grid fingers.

Indium tin oxide (ITO) is a widely used TCO material for SHJ solar cell technology [13]-[16] whereas aluminum doped zinc oxide $(A Z O)$ is an interesting substitute due to the high abundance of $\mathrm{Zn}$ and the lower costs [17]-[19]. Interestingly, the optoelectrical properties of these TCOs can be strongly affected by the properties of the layers they are deposited on. In our solar cell devices, we systematically observe a higher sheet resistance $\left(R_{\mathrm{Sh}}\right)$ for ITO deposited on nc-Si:H layers than on a-Si:H. This is not the case for AZO.

Ritzau et al. [14] observed a strong increase of the carrier concentration $\left(N_{e}\right)$ in ITO deposited on p-doped a-Si:H upon thermal annealing whereas no $N_{e}$ increase was observed for ITO deposited on bare glass. This gave a strong indication that the ITO can be doped by hydrogen $(H)$ of underlying layers. Considering these findings, Haschke et al. [20] observed $R_{\mathrm{sh}}$ discrepancies between ITO deposited on glass, on (p)a-Si:H coated glass and on (p)nc-Si coated glass, which they explained with the same phenomenon.

In this article, we analyze electrical, structural, and chemical properties of ITO and AZO deposited on different thin-film 
TABLE I

THIN-FILM Si LAYERS USED AS SUBSTRATES FOR THE TCOS

\begin{tabular}{cccccc}
\hline \hline Name & $\begin{array}{c}\text { Thickness } \\
(\mathrm{nm})\end{array}$ & Type & Doping & $\begin{array}{c}F_{\mathrm{c}}^{\mathrm{Si}} \\
(\%)\end{array}$ & $\begin{array}{c}\text { RMS } \\
\text { roughness } \\
(\mathrm{nm})\end{array}$ \\
\hline $\mathrm{aSi}_{12}^{\mathrm{p}}$ & 12 & $\mathrm{a}-\mathrm{Si}: \mathrm{H}$ & (p) Boron & - & 0.9 \\
$\mathrm{aSi}_{12}^{\mathrm{n}}$ & 12 & $\mathrm{a}-\mathrm{Si}: \mathrm{H}$ & (n) phosphorous & - & 0.6 \\
$\mathrm{aSi}_{100}^{\mathrm{i}}$ & 100 & $\mathrm{a}-\mathrm{Si}: \mathrm{H}$ & (i) intrinsic & 0 & 0.5 \\
$\mathrm{ncSi}_{12}^{\mathrm{n}}$ & 12 & $\mathrm{nc-Si}: \mathrm{H}$ & (n) phosphorous & - & 2.3 \\
$\mathrm{ncSi}_{12}^{\mathrm{p}}$ & 12 & $\mathrm{nc}-\mathrm{Si}: \mathrm{H}$ & (p) Boron & - & 1.9 \\
$\mathrm{ncSi}_{100}^{\mathrm{n}}$ & 100 & $\mathrm{nc}-\mathrm{Si}: \mathrm{H}$ & (n) phosphorous & 40 & 3.5 \\
$\mathrm{ncSi}_{100}^{\mathrm{i}}$ & 100 & nc-Si:H & (i) intrinsic & 80 & 9.8 \\
\hline \hline
\end{tabular}

silicon substrates. The aim is to elucidate the reasons behind the previously mentioned variations in TCO conductivity when implemented in devices. We observe that in the case of the ITO the electron mobility $\mu_{e}$ is strongly affected by the underlying $\mathrm{Si}$ layer. In contrast, the $N_{e}$ shows similar behavior independently of substrate type. We find that $\mu_{e}$ decreases with increased thinfilm silicon layer crystalline fraction $\left(\mathrm{F}_{\mathrm{c}}^{\mathrm{Si}}\right)$ that promotes a higher root mean square (rms) roughness of the substrate layer. We ascribe this $\mu_{e}$ decrease to increased grain boundary scattering due to decreased mean grain size $(L)$ and/or increased grain barrier trap density $\left(D_{t}\right)$. This behavior is of major relevance for the optimization of ITO for SHJ solar cells.

\section{EXPERIMENTAL}

\section{A. Layer Stacks Preparation and Characterization}

For the investigated material stacks, $1.1 \mathrm{~mm}$ thick Corning Eagle XG glasses were used as substrates. Intrinsic and doped thin-film silicon layers were deposited by plasma-enhanced chemical vapor deposition (PECVD) in an AKT1600 cluster tool from Applied Materials with a parallel electrode configuration operated at $13.56 \mathrm{MHz}$. To resemble SHJ solar cell-like grown thin-film silicon layers, a $5 \mathrm{~nm}$ (i)a-Si:H was initially deposited on the glass substrates. On top of the (i)a-Si:H layer, thin-film silicon layers as given in Table I were deposited. A thickness of 12 $\mathrm{nm}$ was chosen since it is relevant for SHJ solar cell technology and $100 \mathrm{~nm}$ thick layers were investigated to compare layers that have a further developed structure. Crystalline fraction $F_{\mathrm{c}}^{\mathrm{Si}}$ of the $100 \mathrm{~nm}$ thick layers was derived from Raman spectroscopy as described in [21] with $F_{c}^{\mathrm{Si}}=I_{c} /\left(I_{a}+m I_{c}\right)$, where $I_{a}$ is the Raman peak intensity associated with the amorphous phase, $I_{c}$ is the intensity associated with the crystalline phase and $m$ is a corrective factor which was set to 1 in this article.

The rms roughness of the layers was determined via atomic force microscopy.

TCO layers were deposited in an in-line dc magnetron sputtering system from Leybold Optics (A600V7). ITO layers were sputtered from a $95 \mathrm{wt} \% \mathrm{In} 2 \mathrm{O} 3$ and $5 \mathrm{wt} \% \mathrm{SnO} 2$ ceramic tube target and the AZO films were sputtered from a $99 \mathrm{wt} \% \mathrm{ZnO}$ and $1 \mathrm{wt} \% \mathrm{Al}_{2} \mathrm{O}_{3}$ ceramic tube target. Both TCOs were deposited at an approximate substrate temperature of $140 \pm 20^{\circ} \mathrm{C}$ with oxygen flow ratios $r\left(O_{2}\right)=q\left(O_{2}\right) / q\left(A r+O_{2}\right)$ of $1.6 \%$ and $0.2 \%$, respectively. The samples were annealed on a hot-plate at a temperature of $210{ }^{\circ} \mathrm{C}$ for $15 \mathrm{~min}$ in the ambient atmosphere as it is also done for the curing process after silver-grid screenprinting used for our solar cells. A TCO thickness of $110 \mathrm{~nm}$ on a flat substrate was chosen since this results in a $75 \pm 10 \mathrm{~nm}$ layer perpendicular to the pyramid surfaces on a textured wafer, which is required for ideal anti-reflection properties on solar cell devices.

The TCO layers electron mobility, $\mu_{e}$, and concentration, $N_{e}$, were determined by Hall measurements with an Ecopia HMS 3000 system applying the van der Pauw method. Three samples were prepared for Hall measurements for each variation. The mean values and their average deviation are indicated in the graph. Scanning electron microscopy (SEM) was carried out in a MERLIN system from Zeiss on the layers to study and compare their surface morphology. Furthermore, secondary ion mass spectroscopy (SIMS) measurements were carried out on selected samples. SIMS measurements were performed employing the CAMECA SC Ultra instrument under ultra-high vacuum, usually of $4 \times 10^{-10} \mathrm{mbar}$. Enough depth resolution was obtained for negative ions detection mode by using a low impact energy of $100 \mathrm{eV}$ for a Cs + primary beam scanned over $250 \times 250 \mu \mathrm{m}^{2}$. The extremely low impact energy of primary ions $(100 \mathrm{eV})$ not only ensure a desired depth resolution but almost completely eliminate the mixing effect and thus most signals have very sharp interfaces. Thus, the hydrogen decay curve can be attributed to actual diffusion and not to any potential SIMS-related artifacts [22], [23]. The layer stacks for SIMS measurements were prepared on $200 \mu \mathrm{m}$ thick polished Czochralski wafers with the same layer stacks as on glass. P-doped wafers were used for (n)nc-Si:H samples and n-doped wafers for (p)a-Si:H samples. This in order to electrically decouple the thin-film layers from the wafer and measure Hall parameters.

Transmission electron microscopy (TEM) was carried out using a Jeol JEM2200FS equipped with a Nanomegas ASTAR system. Samples were prepared using a focused ion beam (FIB). High-resolution and dark/bright-field imaging observation in conjunction with scanning nano-beam electron diffraction (NBED) acquisition were employed. The NBED datasets contain $128 \times 128$ diffraction patterns, acquired at positions with a separation of $1.5 \mathrm{~nm}$ along both lateral dimensions. The NBED datasets were calibrated using the intense central spot as a reference, and virtual bright- and dark-field images were obtained using a circular detector mask.

\section{B. Solar Cells Preparation and Characterization}

Solar cells were prepared using n-type Czochralski (CZ) silicon wafers (c-Si) with $5 \Omega \mathrm{cm}$ resistivity. The as-cut wafers were wet-chemically etched to eliminate the sawing damage. Its surfaces were then textured in $\mathrm{KOH}$ to obtain random pyramids with heights in the range of $1-3 \mu \mathrm{m}$ with $<111>$ oriented facets and resulting in $125 \mu \mathrm{m}$ thick wafers. After RCA cleaning and a dip in a $1 \%$ diluted hydrofluoric acid solution, intrinsic and doped silicon layers were deposited in the PECVD reactor system as described in Section II-A. An i/p a-Si:H stack was deposited on the rear-side to form the hole contact (rear-junction). At the front side an electron contact was formed by depositing an (i)a-Si:H 


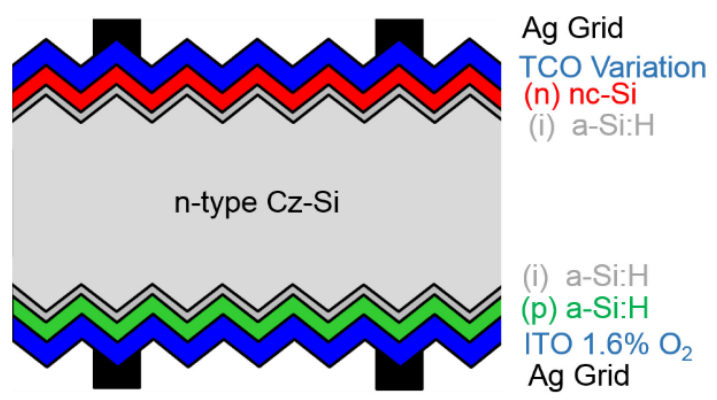

Fig. 1. Standard processed rear-junction SHJ solar cell schematic cross section.

with an (n)nc-Si:H layer on top. The solar cells were prepared by varying the front TCO layers as described in Fig. 4 . The back TCO was made with the $1.6 \% \mathrm{O}_{2}$ partial flow ITO with the process parameters as described in Section II-A. The TCO layers were sputtered through aligned shadow masks on both sides of the wafer to define $144-\mathrm{cm}^{2}$ sized cells and three transfer length method (TLM) structures per wafer.

A silver grid with a 1670 and $800 \mu \mathrm{m}$ finger-pitch was screenprinted at the front and back of the solar cells, respectively. The grid was cured at $210{ }^{\circ} \mathrm{C}$ for 15 min on a hot-plate under atmospheric conditions. Fig. 1 shows the schematic cross section of the described rear-junction SHJ solar cell.

The solar cells were characterized using current densityvoltage $(J-V)$ measurements in the dark and under an AM1.5G spectrum at standard test conditions in a Wacom WXS-155S-L2 dual source class $\mathrm{AAA}+$ sun simulator. Resistance measurements were made on the TLM structures to calculate the TCO sheet resistance $\left(R_{\mathrm{sh}}\right)$ on devices. To derive the TCO $R_{\mathrm{sh}}$ from an (n) wafer/(i)a-Si:H/(n)nc-Si:H stack from TLM structures we used a parallel resistance model as proposed by Bivour et al. [5]. According to this model $R_{\mathrm{sh}, \mathrm{TCO}}$ can be determined from

$$
\mathrm{R}_{\text {ShTCO }}=1 /\left(\frac{1}{R_{\text {shTLM }}}-\frac{1}{R_{\text {shWafer }}}\right)
$$

with $R_{\mathrm{ShTCO}}$ being the TCO $R_{\mathrm{sh}}, R_{\mathrm{Sh}}$ TLM the $R_{\mathrm{sh}}$ measured via TLM structures, and $R_{\mathrm{shWafer}}$ the $R_{\mathrm{sh}}$ of the wafer. The latter was obtained from quasi-steady state photo conductance decay measurements for each sample. The average wafer $R_{\mathrm{sh}}$ was $380 \pm 10 \Omega$. The effect of contact resistivity is neglected and we assume the value is low enough and permits current flow into the wafer. $R_{s}$ values of the solar cells were determined from the dark to light $J-V$ curve comparison according to [24].

\section{RESULTS AND DISCUSSION}

\section{A. Thin-Film Silicon Layer Properties}

In Table I, the different thin film silicon layers investigated are presented. The layer names indicate the layer type (a-Si or nc-Si), the doping type (i, p, or n) as superscript and the layer thickness (12 or $100 \mathrm{~nm}$ ) as subscript. The properties presented in Table I show that the $\mathrm{F}_{\mathrm{c}}^{\mathrm{Si}}$ of the layers increases from $0 \%$ for an amorphous layer, $\mathrm{aSi}_{100}^{\mathrm{i}}$, to $80 \%$ for the layer with highest $\mathrm{F}_{c}^{\mathrm{Si}}$, i.e., $\mathrm{ncSi}_{100}^{i}$. For the standard (n)nc-Si:H layer used in the

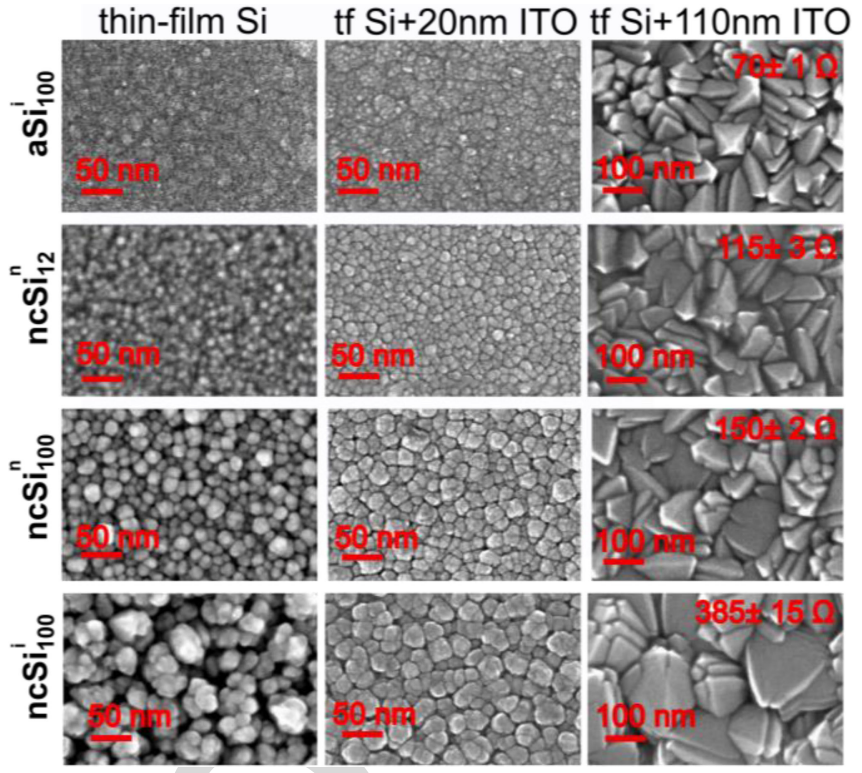

Fig. 2. SEM micrographs of thin-film silicon layers on glass (first column), with $20 \mathrm{~nm}$ ITO (second column) and with $110 \mathrm{~nm}$ ITO (third column) layers on top. The thin-film silicon layer substrate type is indicated at the left of the first column, detailed properties of the layers can be found in Table I. Length scales are indicated for each image. Sheet resistance values measured on the $110 \mathrm{~nm}$ ITO layers are indicated in the third column.

solar cells, $\mathrm{ncSi}_{12}^{\mathrm{n}}$, no Raman spectrum could be measured since it is device relevantly thin at $12 \mathrm{~nm}$. However, it is well known from the literature that the $\mathrm{F}_{c}^{\mathrm{Si}}$ of the nc-Si:H layers will lower with decreased film thickness [8], [9], [19], [20]. Fioretti et al. recently reported that the PECVD deposited p-doped nc-Si:H layers, at the cell level, can increase its crystallinity when reducing the deposition temperature, from 200 to $125^{\circ} \mathrm{C}$ [12]. However, this trend was not followed in the case of the n-doped nc-Si:H layers that are the main focus of our article. Hence, we can assume that $\mathrm{ncSi}_{12}^{n}$ and $\mathrm{ncSi}_{12}^{p}$ layers have an $\mathrm{F}_{c}^{\mathrm{Si}}$ between $0 \%$ and $40 \%$.

We see a correlation of the $\mathrm{F}_{c}^{\mathrm{Si}}$ and the rms roughness. The rms roughness steadily increases with layer $\mathrm{F}_{c}^{\mathrm{Si}}$ from $0.5 \mathrm{~nm}$ for $\mathrm{aSi}_{100}^{i}$ to $9.8 \mathrm{~nm}$ for $\mathrm{ncSi}_{100}^{i}$. Furthermore, SEM micrographs shown in the first column of Fig. 2 reveal that the $\mathrm{F}_{c}^{\mathrm{Si}}$ and the rms roughness correlate with the mean grain size of the films as well. It is worth mentioning that the surface topographies did not show any noticeable change between as deposited and annealed state.

The SEM micrographs in the second column of Fig. 2 show corresponding substrates with a $20 \mathrm{~nm}$ ITO layer deposited on top. These images clearly show that at its initial growth stage the ITO adopts a similar morphology as the underlying silicon layers. However, when analyzing the surface morphology of the $110 \mathrm{~nm}$ ITO layers seen in column 3 of Fig. 2, we see that the ITO layers reconfigure their structure and acquire a sharp polycrystalline grain shape, which is a typical morphology for ITO sputtered under conditions as described in Section II-A [25]. The $R_{\mathrm{sh}}$ values observed in Fig. 2 for the $110 \mathrm{~nm}$ ITO layers show the discrepancies of the conductivity of these layers depending 


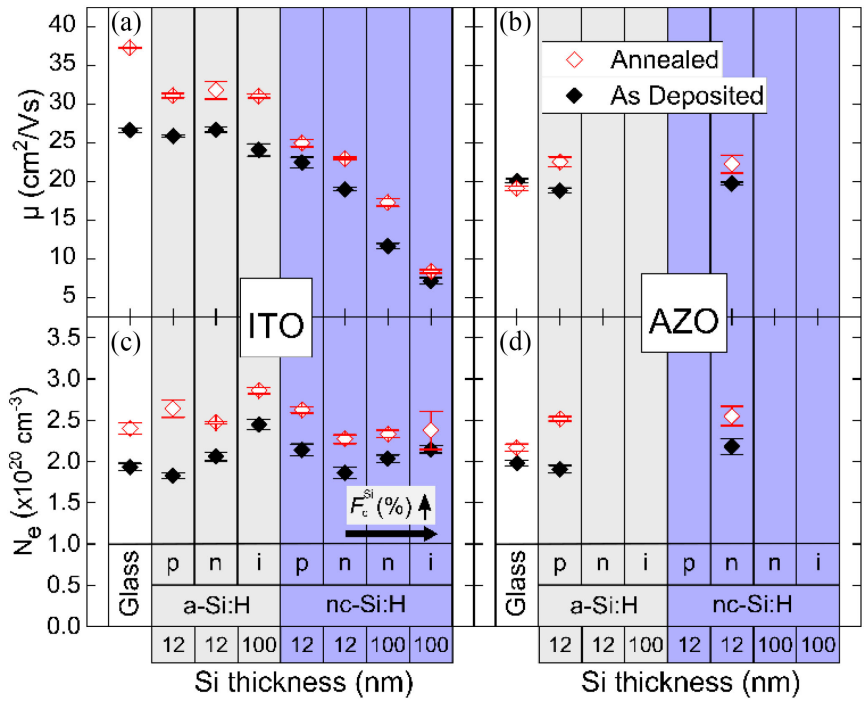

Fig. 3. Hall electron mobility $\mu_{e}$ of $105 \pm 10 \mathrm{~nm}$ thick (a) ITO and (b) AZO layers deposited on bare and coated glass with varied thin-film silicon layers and Hall carrier concentration $N_{e}$ of same (c) ITO and (d) AZO layers. Doping and layer type are indicated on top of the thin film silicon thicknesses. The arrow indicates the increase of crystallinity fraction $\mathrm{F}_{\mathrm{C}}^{\mathrm{Si}}$ for the corresponding thin film silicon layers. on the underlying substrate. ITO on $\mathrm{aSi}_{100}^{i}$ exhibits $R_{\mathrm{sh}}=70 \pm$ $1 \Omega$ whereas ITO on $\mathrm{ncSi}_{100}^{i}$ has $R_{\mathrm{sh}}=385 \pm 15 \Omega$.

On the thick nc-Si ncSi ${ }_{100}^{i}$ layer, the ITO presents clearly larger crystals as compared to the thick amorphous as well as both 12-nm thin nc-Si under layers. Differences between TCO layers on thin $\mathrm{aSi}_{12}^{p}$ and $\mathrm{ncSi}_{12}^{n}$ layers are further investigated with TEM microscopy in Section III-C.

\section{B. TCO Electrical Properties}

The analyzed TCO layers were designed for the application on SHJ solar cells. Therefore, the process parameters were optimized for the highest $\mu_{e}$ possible at an $N_{e}$ that has low free carrier absorption typically around a value of $2 \times 10^{20} \mathrm{~cm}^{-3}$ [26].

For both materials, ITO and AZO, the concentration of carriers is determined by the level of extrinsic doping and intrinsic acceptors as oxygen interstitials or metal vacancies. The formation of the acceptor type defects is strongly promoted by the addition of oxygen to the growth process [27]. Hence, it is possible to control the optoelectric properties through adjustment of the oxygen partial pressure during deposition [28], [29].

In this article, the oxygen flow rate was chosen to lead to the desired $N_{e}$ of $2 \times 10^{20} \mathrm{~cm}^{-3}$ on glass substrates and the deposition conditions were maintained for all studied samples. As a result, the $N_{e}$ for films grown on the various substrates under investigation are very similar. From Fig. 3(c) and (d), we can see that $N_{e}$ remains in a range of $2.1 \pm 0.3 \times 10^{20} \mathrm{~cm}^{-3}$ for layers in as-deposited state and increases to $2.4 \pm 0.3 \times$ $10^{20} \mathrm{~cm}^{-3}$ after annealing for both ITO and AZO.

As we see from Fig. 3(a), ITO grown on layer $\mathrm{ncSi}_{12}^{n}$ has a lower $\mu_{e}$ in comparison to the one on $\mathrm{aSi}_{12}^{p}$. In contrast, in Fig. 3(b), the AZO shows the same $\mu_{e}$ on $\mathrm{aSi}_{12}^{p}$ and $\mathrm{ncSi}_{12}^{n}$.

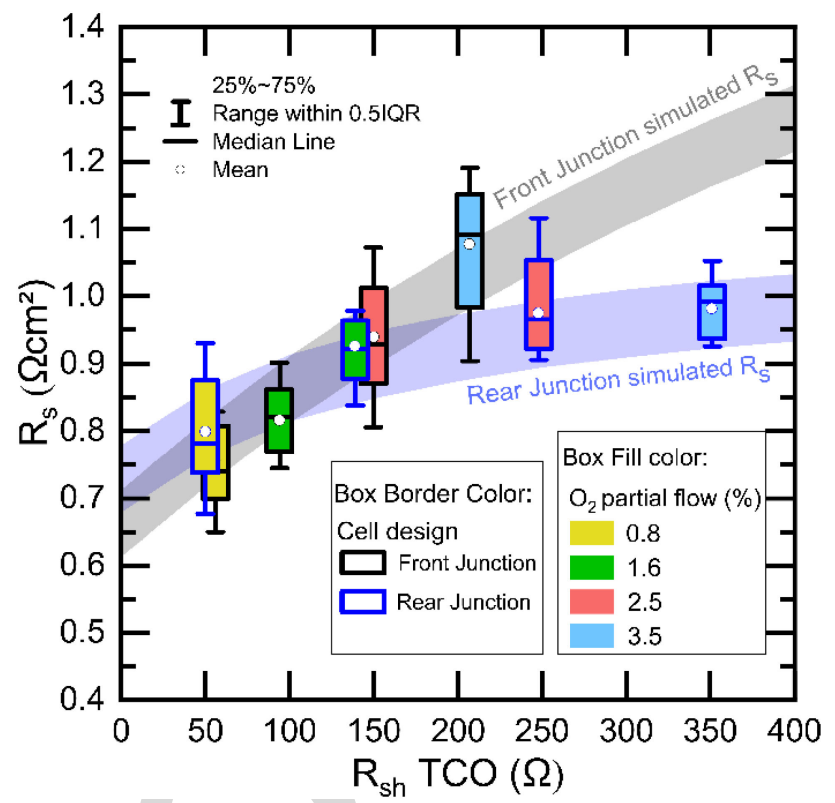

Fig. 4. Rear- and front-junction SHJ solar cells series resistance $R_{s}$ versus ITO sheet resistance $R_{\mathrm{sh}}$. The front contact ITO $R_{\mathrm{sh}}$ was varied through the $\mathrm{O}_{2}$ process partial flow. The back contact is identical for all cells. Simulated $R_{\mathrm{S}}$ versus $R_{\mathrm{Sh}}$ TCO curves for rear- and front-junction devices after [30] are included. The simulation curves include an error of $\pm 0.05 \Omega \mathrm{cm}^{2}$. The boxplots show values of 28 cells in two wafers per box.

As a result, $\mu_{e}$ is around $22 \mathrm{~cm}^{2} / \mathrm{Vs}$ for both ITO and AZO when deposited on $\mathrm{ncSi}_{12}^{n}$. The ITO presents an even lower $\mu_{e}$ of $8.4 \pm 0.2 \mathrm{~cm}^{2} / \mathrm{Vs}$ when grown on the $\mathrm{ncSi}_{100}^{i}$ layer. This behavior shows a clear correlation of a decreased $\mu_{e}$ of the ITO with higher $\mathrm{F}_{c}^{\mathrm{Si}}$, rms surface roughness and grain size of the previously described silicon underlying layers.

To investigate whether the $\mu_{e}$ differences are related to the doping type of the thin silicon films, we compare ITO layers deposited on intrinsic $\left(\mathrm{aSi}_{100}^{i}\right)$, phosphorous doped $\left(\mathrm{aSi}_{12}^{n}\right)$, and boron-doped $\left(\mathrm{aSi}_{12}^{p}\right)$ a-Si:H with its counterparts on doped nc$\mathrm{Si}: H$ layers $\left(\mathrm{ncSi}_{100}^{i}, \mathrm{ncSi}_{12}^{p}, \mathrm{ncSi}_{12}^{n}\right.$, respectively. From Fig. 3(a), we confirm that the ITO presents in all cases lower $\mu_{e}$ when deposited on nc-Si:H than on a-Si:H independently of the type of doping.

The same behavior was observed in finished solar cells, namely a conductivity decrease of ITO layers grown on nc-Si as compared to a-Si contact layers. To demonstrate this, in Fig. 4, we show the result of different front ITO $R_{\mathrm{sh}}$ by oxygen-flow variation (the back TCO contact is the same for all cells) and its impact on device series resistance $R_{s}$ for front-junction and rear-junction solar cells. The results show that the front ITO deposited with the same process conditions on (n)nc-Si:H (rearjunction cells) generally presents higher $R_{\mathrm{Sh}}$ than its counterparts deposited on (p)a-Si:H layers (front-junction cells). The ITO $R_{\mathrm{sh}}$ differences have a direct impact on the solar cells $R_{s}$ and hence on its Fill-Factor $(F F)$ depending on the solar cell design [30]. After optimization, solar cells with ITO $\left(J_{\mathrm{sc}}=39.0 \mathrm{~mA} / \mathrm{cm}^{2}\right.$; $\left.V_{\mathrm{oc}}=742 \mathrm{mV} ; F F=81.1 \%\right)$ and $\mathrm{AZO}\left(J_{\mathrm{sc}}=39.1 \mathrm{~mA} / \mathrm{cm}^{2}\right.$; $\left.V_{\mathrm{oc}}=741 \mathrm{mV} ; F F=81.2 \%\right)$ front electrodes both lead to the same certified (ISFH CalTeC) efficiency of $23.5 \%$. Interestingly, 
(p)a-Si:H-12 nm
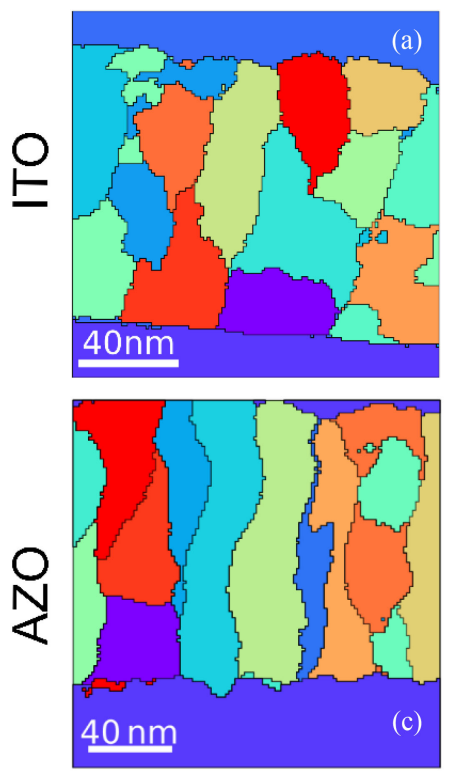

(n)nc-Si:H- 12 nm
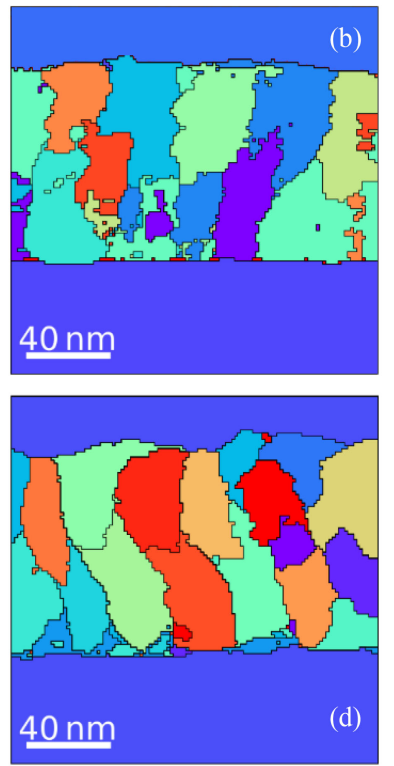

Fig. 5. Scanning NBED acquisitions of $105 \pm 10 \mathrm{~nm}$ ITO (a), (b) and AZO (c), (d) on (p)a-Si:H and (n)nc-Si:H coated c-Si wafers, obtained from TEM imaging observations. The samples are prepared on $200-\mu \mathrm{m}$-thick Czochralski $\mathrm{c}$-Si wafers positioned at the bottom in the images. The images show only crystals from the TCO materials.

the ITO $R_{\mathrm{sh}}$ discrepancy increases for the higher $\mathrm{O}_{2}$ partial flow ITO. This effect was also observed by Haschke et al. [20] for ITO deposited on (p)a-Si:H and on (p)nc-Si:H coated glass. The analysis in this article is based on flat substrates. Nonetheless, the influence of textured substrates on the studied effect is worth of further investigation.

\section{Structural Properties}

Fig. 5 shows the microstructure of the ITO and AZO obtained by a cluster analysis of the scanning NBED data that was acquired in the TEM measurements. Fig. 5(a) and (b) shows the polycrystalline ITO layers deposited on $\mathrm{aSi}_{12}^{p}$ and $\mathrm{ncSi}_{12}^{n}$ layers, respectively. It is noticeable that the ITO layer on $\mathrm{ncSi}_{12}^{n}$ shows smaller and more fractured domains in its initial growth stages. After this initial growing stage, the layer reconfigures its microstructure and resembles the shapes of the ITO grains on $\mathrm{aSi}_{12}^{p}$. This is consistent with the top view SEM micrographs of the 110-nm ITO layers shown in Fig. 2. We can observe that the average grain size of the layer on $\mathrm{ncSi}_{12}^{n}$ is smaller than that on $\mathrm{aSi}_{12}^{p}$. Furthermore, the grain boundaries for the ITO on $\mathrm{ncSi}_{12}^{n}$ are more irregular.

On the other hand, the AZO is less affected by the underlying layer as seen from Fig. 5(c) and (d). The typical columnar growth for this material [31] can be seen in the images. That correlates well with the unchanged $\mu_{e}$ of the AZO.

In Section III-E, the behavior of $\mu_{e}$ is discussed in detail considering the findings from the different characterization methods.

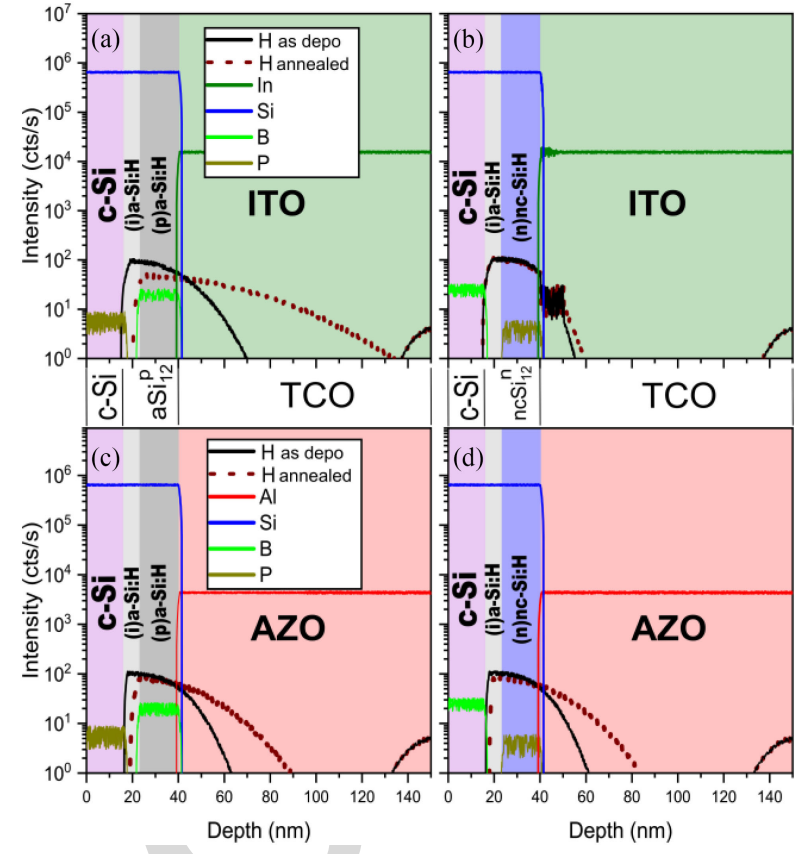

Fig. 6. SIMS measurements of ITO on (a) (i)a-Si:H / (p)a-Si:H ( aSi ${ }_{12}^{\mathrm{p}}$ ) layer and (b) (i)a-Si:H / (n)nc-Si:H (ncSin ) layer. As well as AZO on (c) (i)a-Si:H/ (p)a-Si:H ( $\mathrm{aSi}_{12}^{\mathrm{p}}$ ) layer and (d) (i)a-Si:H / (n)nc-Si:H ( $\left.\mathrm{ncSi}_{12}^{\mathrm{n}}\right)$ layer. Indium (In), Aluminum (Al), Silicon (Si), Boron (B), and Phosphorous (P) signals on as deposited and annealed state overlap almost identically within noise error. Hydrogen $(\mathrm{H})$ straight lines are for as deposited state and dashed lines for annealed state.

\section{Role of Hydrogen Diffusion}

From previous studies, it is known that hydrogen diffusion into TCO materials can play a significant role in their electrical properties [14], [32], [33]. To understand the role of diffused hydrogen in the TCO materials SIMS measurements were carried out.

Fig. 6 shows SIMS measurements of ITO and AZO grown on $\mathrm{aSi}_{12}^{p}$ and $\mathrm{ncSi}_{12}^{n}$ layers in as deposited state and after annealing. The annealing process has a noticeable effect on the $H$ diffusion. All other elements remain almost unchanged.

Interestingly, we observe a clear difference in $H$ penetration depth for ITO depending on the underlying Si layer. For ITO grown on a $\mathrm{ncSi}_{12}^{n}$ type layer, a $H$ signal is detected until a depth of approx. $55 \mathrm{~nm}$, whereas the layer deposited on the $\mathrm{aSi}_{12}^{p}$ type layer presents a penetration depth of $70 \mathrm{~nm}$ in as-deposited state as we can see from Fig. 6(a) and (b). After annealing, the $H$ further diffuses into the layer and increases its depth to up to $130 \mathrm{~nm}$ for $\mathrm{aSi}_{12}^{p}$ but only to $60 \mathrm{~nm}$ for $\mathrm{ncSi}_{12}^{n}$. On the other hand, the AZO shows very similar $H$ penetration depths independently of the layer on which it is deposited. The depths are of 61 and $62 \mathrm{~nm}$ in as deposited state and these increase to 82 and $87 \mathrm{~nm}$ after the annealing step for the $\mathrm{ncSi}_{12}^{n}$ and $\mathrm{aSi}_{12}^{p}$ substrates, respectively. Another effect worth mentioning is that samples with $\mathrm{aSi}_{12}^{p}$ layers exhibit a stronger $H$ depletion from the (i)a-Si:H/c-Si interface as seen in the SIMS profiles after annealing. Ritzau et al. [14] already stressed out, that a boron (p) doped a-Si:H layer allows more effusion of hydrogen through 
decrease of its activation energy in comparison to a phosphorous (n) doped layer. This effect promotes the extraction of hydrogen from the (i)a-Si:H layer and might be a reason for degradation of the passivating effect of dangling bonds at the (i)a-Si:H/c-Si interface [34]. Interestingly the ITO layer grown on $\mathrm{ncSi}_{12}^{n}$ that obstructs the diffusion into the TCO clearly maintains the highest amount of hydrogen at the $\mathrm{c}-\mathrm{Si} /(\mathrm{n}) \mathrm{nc}-\mathrm{Si}: \mathrm{H}$ interface, which might be beneficial for passivation purposes.

\section{E. Discussion: Electron Mobility Behavior}

In order to understand the differences in $\mu_{e}$ for the ITO layers grown on different substrates it is important to consider the various scattering processes limiting the $\mu_{e}$ in TCO layers. In the past years, authors have made considerable efforts to explain the $\mu_{e}$ limitation in both AZO and ITO [35], [36].

The maximum $\mu_{e}$ achievable for a given carrier concentration is only limited by phonon scattering and ionized impurity scattering. For ITO with a carrier concentration of $2 \times 10^{20} \mathrm{~cm}^{-3}$ carriers, Preissler et al. calculated an $\mu_{e}$ of approx. $70 \mathrm{~cm}^{2} / \mathrm{Vs}$, which is by far higher than our values. Neglecting the unknown influence of possible neutral impurity scattering and dislocation scattering, the main reasons for this deviation can be compensation [35] and grain boundary scattering [37], [38].

Compensation not only influences $\mu_{e}$, but also determines the $N_{e}$ in the films. Seeing that our films exhibit very similar carrier concentrations regardless of the substrate, we conclude that the compensation is mainly determined by the growth conditions rather than the substrate and its influence on the structure of the TCO layers. Hence, we can assume that compensation is similar for all samples and only minor changes might occur during annealing. This context leaves the grain boundary scattering as the main possible mechanism influencing the variation of $\mu_{e}$. Equation (2) shows the expression for effective mobility $\mu_{\text {eff }}$ developed by Seto [39]

$$
\mu_{\mathrm{eff}}=\frac{\mathrm{eL}}{\sqrt{2 \pi \mathrm{m}^{*} \mathrm{kT}}} \exp \left(-\frac{\mathrm{E}_{b}}{\mathrm{kT}}\right)
$$

where $L$ is the grain size, $m *$ is the electron effective mass, $E_{b}$ is the energetic barrier height at the grain boundary, $T$ the sample temperature, and $e$ and $k$ are the elementary charge and the Boltzmann constant, respectively. From (2), we see that the grain size affects the material $\mu_{\text {eff }}$ linearly. Hence, the smaller fractured grain features seen on the ITO deposited on $\mathrm{ncSi}_{12}^{n}$ in comparison to $\mathrm{aSi}_{12}^{p}$ layers can partially explain the diminished $\mu_{e}$ effect (see Fig. 5). A further effect to be considered is the influence of the energetic barrier $E_{b}$. Depending on the grain size $L$, the carrier concentration $N_{e}$ and the trap density at grain boundaries $D_{t}$, two expressions for the barrier height $E_{b}$ are applicable [37]

$$
\begin{aligned}
\mathrm{E}_{b}=\frac{\mathrm{e}^{2} \mathrm{D}_{t}^{2}}{8 \varepsilon \varepsilon_{0} \mathrm{~N}_{e}} & \text { for } \mathrm{LN}_{e}>\mathrm{D}_{t} \\
\mathrm{E}_{b}=\frac{\mathrm{e}^{2} \mathrm{~L}^{2} \mathrm{~N}_{e}}{8 \varepsilon \varepsilon_{0}} & \text { for } \mathrm{LN}_{e}<\mathrm{D}_{t}
\end{aligned}
$$

where $\varepsilon \varepsilon_{0}$ is the static dielectric constant.

Typical $D_{t}$ values for the TCO layers investigated here lie between $1 \times 10^{12}$ and $3 \times 10^{13} \mathrm{~cm}^{-2}$ [14], [37]. Thus, even for a very small mean $L$ value of $5 \mathrm{~nm}$, we have $L N_{e}>D_{t}$. Hence, $D_{t}$ is dominating the $E_{b}$ height according to (2a).

Under this circumstances, an increased $D_{t}$ at grain boundaries can be a further reason for decreased $\mu_{e}$ of the ITO layers on nc-Si:H.

From the measured SIMS profiles shown in Fig. 6, we can conclude that in none of the studied cases boron or phosphorous diffuses into the TCO layers. Hence, the diffusion of these elements is not a source of additional scattering impurities and the effect of lowered $\mu_{e}$ is independent of these dopants as it was already concluded from Fig. 3. A further effect that can have an impact on the $\mu_{e}$ of the layers is the diffusion of hydrogen into the TCOs coming from the hydrogenated thin-film silicon layers. We see from the SIMS profiles in Fig. 6 that the ITO receives less hydrogen from a $\mathrm{ncSi}_{12}^{n}$ layer. In contrast, the hydrogen penetrates deeper into the ITO layer grown on $\mathrm{aSi}_{12}^{p}$. We observe, however, that both the ITO layers on $\mathrm{aSi}_{12}^{p}$ and $n c \mathrm{Si}_{12}^{n}$ show an increase of $\mu_{e}$ upon annealing, so the potential influence of hydrogen diffusion remains unclear. In the case of the AZO, however, the layers present very similar hydrogen profiles, which are consistent with the almost equal $\mu_{e}$ that both layers show.

A clarification of the phenomena would require determination of the potential barriers from temperature-dependent Hall measurements, which are outside the scope of this article.

\section{CONCLUSION}

ITO deposited on nc-Si:H presents lower $\mu_{e}$ in comparison to same layers deposited on a-Si:H. This is related to an increased RMS roughness of the nc-Si:H correlating with thin-film silicon crystalline fraction and increased grain size. We find from TEM measurements that a surface with increased RMS roughness promotes the growth of smaller fractured grain features of the ITO at initial growth stages. In this context, possible explanations for the decreased $\mu_{e}$ are the decreased ITO mean grain size or an increase of the trap density at the materials' grain boundaries. Furthermore, we observe a lower hydrogen penetration depth for ITO layers grown on nc-Si than on a-Si as observed in SIMS profiles.

On the contrary, the AZO presents almost identical $\mu_{e}$ when deposited on nc-Si:H and a-Si:H which is consistent with the similarity in structural properties observed from TEM and diffusion profiles measured with SIMS.

ITO grown on an n-doped nc-Si:H layer clearly shows lesser out-diffusion of hydrogen from the c-Si/(i)a-Si:H interface as compared to the ITO grown on p-doped a-Si:H. The impact of this behavior on device passivation properties is relevant for further investigation.

The previously described phenomena should be considered during the development of carrier selective contacts for SHJ solar cells.

\section{ACKNOWLEDGMENT}

We would like to thank the coworkers at HZB for their support: K. Mayer-Stillrich and M. Hartig for sputtering depositions, M. Zelt and T. Henschel for support with PECVD, H. Rhein for 
screen-printing processing, M. Setzchen for device characterization and H. Kropf for FIB sample preparation, and K. Mack for Raman spectroscopy measurements. A. Cruz gratefully acknowledges the scholarship support from the Mexican National Council for Science and Technology (CONACYT).

\section{REFERENCES}

[1] J. Haschke, O. Dupré, M. Boccard, and C. Ballif, "Silicon heterojunction solar cells: Recent technological development and practical aspects - From lab to industry," Sol. Energy Mater. Sol. Cells, vol. 187, pp. 140-153, Dec. 2018.

[2] K. Yoshikawa et al., "Silicon heterojunction solar cell with interdigitated back contacts for a photoconversion efficiency over 26\%," Nat. Energy, vol. 2, no. 5, May 2017, Art. no. 17032.

[3] D. Adachi, J. L. Hernández, and K. Yamamoto, "Impact of carrier recombination on fill factor for large area heterojunction crystalline silicon solar cell with 25.1\% efficiency," Appl. Phys. Lett., vol. 107, no. 23, p. 233506, Dec. 2015.

[4] M. A. Green et al., "Solar cell efficiency tables (Version 53)," Prog. Photovolt. Res. Appl., vol. 27, no. 1, pp. 3-12, 2019.

[5] J. Zhao et al., " $>24 \%$ silicon heterojunction solar cells on meyer burger's on mass production tools and how wafer material impacts cell parameters," in Proc. IEEE 7th World Conf. Photovolt. Energy Convers. (A Joint Conf. 45th IEEE PVSC, 28th PVSEC 34th EU PVSEC), 2018, pp. 1514-1519.

[6] "Hanergy sets new efficiency record for heterojunction module," [Online]. Available: https://www.pv-magazine.com/2019/08/08/hanergy-setsnew-efficiency-record-for-heterojunction-module/. Accessed on Aug. 22, 2019.

[7] S. De Wolf, A. Descoeudres, Z. C. Holman, and C. Ballif, "High-efficiency silicon heterojunction solar cells: A review," Green, vol. 2, no. 1, pp. 7-24, 2012.

[8] A. B. Morales-Vilches, L. Mazzarella, M. Hendrichs, L. Korte, and B. Stannowski, "Nanocrystalline vs. amorphous n-type silicon front surface field layers in silicon heterojunction solar cells: Role of thickness and oxygen content," in Proc. EUPVSEC, 2017, pp. 715-719.

[9] P. Roca i Cabarrocas, N. Layadi, T. Heitz, B. Drévillon, and I. Solomon, "Substrate selectivity in the formation of microcrystalline silicon: Mechanisms and technological consequences," Appl. Phys. Lett., vol. 66, no. 26, pp. 3609-3611, Jun. 1995.

[10] J. P. Seif et al., "Strategies for doped nanocrystalline silicon integration in silicon heterojunction solar cells," IEEE J. Photovolt., vol. 6, no. 5, pp. 1132-1140, Sep. 2016.

[11] G. Nogayet al., "Nanocrystalline silicon carrier collectors for silicon heterojunction solar cells and impact on low-temperature device characteristics," IEEE J. Photovolt., vol. 6, no. 6, pp. 1654-1662, Nov. 2016.

[12] A. N. Fioretti, M. Boccard, R. Monnard, and C. Ballif, "Low-temperature p-type microcrystalline silicon as carrier selective contact for silicon heterojunction solar cells," IEEE J. Photovolt., vol. 9, no. 5, pp. 1158-1165, Sep. 2019.

[13] M. Balestrieri et al., "Characterization and optimization of indium tin oxide films for heterojunction solar cells," Sol. Energy Mater. Sol. Cells, vol. 95, no. 8, pp. 2390-2399, Aug. 2011.

[14] K.-U. Ritzau, T. Behrendt, D. Palaferri, M. Bivour, and M. Hermle, "Hydrogen doping of Indium Tin Oxide due to thermal treatment of hetero-junction solar cells," Thin Solid Films, vol. 599, no. Supplement C, pp. 161-165, Jan. 2016.

[15] B. Aïssa et al., "Impact of the oxygen content on the optoelectronic properties of the indium-tin-oxide based transparent electrodes for silicon heterojunction solar cells," AIP Conf. Proc., vol. 2147, no. 1, Aug. 2019, Art. no. 30001.

[16] J. Haschke et al., "Annealing of silicon heterojunction solar cells: interplay of solar cell and indium tin oxide properties," IEEE J. Photovolt., vol. 9, no. 5, pp. 1202-1207, Sep. 2019.

[17] A. B. Morales-Vilches et al., "ITO-free silicon heterojunction solar cells with $\mathrm{ZnO}: \mathrm{Al} / \mathrm{SiO}_{2}$ front electrodes reaching a conversion efficiency of 23\%," IEEE J. Photovolt., vol. 9, no. 1, pp. 34-39, Jan. 2019.
[18] J.-P. Niemelä et al., "Rear-emitter silicon heterojunction solar cells with atomic layer deposited $\mathrm{ZnO}: \mathrm{Al}$ serving as an alternative transparent conducting oxide to $\mathrm{In}_{2} \mathrm{O}_{3}: \mathrm{Sn}$," Sol. Energy Mater. Sol. Cells, vol. 200, Sep. 2019, Art. no. 109953.

[19] L. Senaud et al., "Aluminium-doped zinc oxide rear reflectors for highefficiency silicon heterojunction solar cells," IEEE J. Photovolt., vol. 9, no. 5, pp. 1217-1224, Sep. 2019.

[20] J. Haschke et al., "Injection-dependent lateral resistance in front-junction solar cells with nc-Si:H and a-Si:H hole selective contact," in Proc. 46th IEEE Photovolt. Specialists Conf., Jun. 2019.

[21] M. Klingsporn et al., "Resolving the nanostructure of plasma-enhanced chemical vapor deposited nanocrystalline $\mathrm{SiO}_{\mathrm{x}}$ layers for application in solar cells," J. Appl. Phys., vol. 119, no. 22, Jun. 2016, Art. no. 223104.

[22] P. P. Michałowski, W. Kaszub, A. Merkulov, and W. Strupiński, "Secondary ion mass spectroscopy depth profiling of hydrogen-intercalated graphene on SiC," Appl. Phys. Lett., vol. 109, no. 1, Jul. 2016, Art. no. 11904.

[23] R. Muydinov et al., "Crystallisation phenomena of $\operatorname{In}_{2} \mathrm{O}_{3}: \mathrm{H}$ films," Materials, vol. 12, no. 2, Jan. 2019, Art. no. 266.

[24] D. Pysch, A. Mette, and S. W. Glunz, "A review and comparison of different methods to determine the series resistance of solar cells," Sol. Energy Mater. Sol. Cells, vol. 91, no. 18, pp. 1698-1706, Nov. 2007.

[25] V. Sittinger et al., "High power pulsed magnetron sputtering of transparent conducting oxides," Thin Solid Films, vol. 516, no. 17, pp. 5847-5859, Jul. 2008.

[26] M. Morales-Masis, S. De Wolf, R. Woods-Robinson, J. W. Ager, and C. Ballif, "Transparent electrodes for efficient optoelectronics," Adv. Electron. Mater., vol. 3, no. 5, p. 1600529, May 2017.

[27] S. Lany and A. Zunger, "Dopability, intrinsic conductivity, and nonstoichiometry of transparent conducting oxides," Phys. Rev. Lett., vol. 98, no. 4, Jan. 2007, Art. no. 45501.

[28] W.-F. Wu and B.-S. Chiou, "Effect of oxygen concentration in the sputtering ambient on the microstructure, electrical and optical properties of radio-frequency magnetron-sputtered indium tin oxide films," Semicond. Sci. Technol., vol. 11, no. 2, pp. 196-202, Feb. 1996.

[29] D. Mergel, "Thin films of ITO as transparent electrodes," Vak. Forsch Prax., vol. 18, no. S1, pp. 15-18, 2006.

[30] A. Cruz et al., "Effect of front TCO on the performance of rear-junction silicon heterojunction solar cells: Insights from simulations and experiments," Sol. Energy Mater. Sol. Cells, vol. 195, pp. 339-345, Jun. 2019.

[31] K. H. Kim, K. C. Park, and D. Y. Ma, "Structural, electrical and optical properties of aluminum doped zinc oxide films prepared by radio frequency magnetron sputtering," J. Appl. Phys., vol. 81, no. 12, pp. 7764-7772, Jun. 1997.

[32] S. Y. Herasimenka, W. J. Dauksher, M. Boccard, and S. Bowden, "ITO/SiO ${ }_{\mathrm{x}}: \mathrm{H}$ stacks for silicon heterojunction solar cells," Sol. Energy Mater. Sol. Cells, vol. 158, Part 1, pp. 98-101, Dec. 2016.

[33] T. Koida, H. Fujiwara, and M. Kondo, "High-mobility hydrogendoped transparent conductive oxide for a-Si:H/c-Si heterojunction solar cells," Sol. Energy Mater. Sol. Cells, vol. 93, no. 6-7, pp. 851-854, Jun. 2009.

[34] S. De Wolf and M. Kondo, "Boron-doped a-Si:H/c-Si interface passivation: Degradation mechanism," Appl. Phys. Lett., vol. 91, no. 11, Sep. 2007, Art. no. 112109 .

[35] D. C. Look et al., "Self-compensation in semiconductors: The Zn vacancy in Ga-doped ZnO," Phys. Rev. B, vol. 84, no. 11, Sep. 2011, Art. no. 115202

[36] N. Preissler, O. Bierwagen, A. T. Ramu, and J. S. Speck, "Electrical transport, electrothermal transport, and effective electron mass in single-crystalline $\mathrm{In}_{2} \mathrm{O}_{3}$ films," Phys. Rev. B, vol. 88, no. 8, Aug. 2013, Art. no. 85305.

[37] K. Ellmer and R. Mientus, "Carrier transport in polycrystalline transparent conductive oxides: a comparative study of zinc oxide and indium oxide," Thin Solid Films, vol. 516, no. 14, pp. 4620-4627, May 2008.

[38] C. Lohaus et al., "Enhancing electrical conductivity of room temperature deposited $\mathrm{Sn}$-doped $\operatorname{In}_{2} \mathrm{O}_{3}$ thin films by hematite seed layers," Appl. Phys. Lett., vol. 112, no. 15, Apr. 2018, Art. no. 152105.

[39] J. Y. W. Seto, "The electrical properties of polycrystalline silicon films," J. Appl. Phys., vol. 46, no. 12, pp. 5247-5254, Dec. 1975. 


\section{GENERAL INSTRUCTION}

- Authors: We cannot accept new source files as corrections for your article. If possible, please annotate the PDF proof we have sent you with your corrections and upload it via the Author Gateway. Alternatively, you may send us your corrections in list format. You may also upload revised graphics via the Author Gateway.

- Authors: Please confirm the name of the corresponding author.

\section{QUERIES}

Q1. Author: Please confirm or add details for any funding or financial support for the research of this article.

Q2. Author: Acronym "SIMS" has two expansions "secondary ion mass spectrometry" and "secondary ion mass spectroscopy." Please check.

Q3. Author: Please check whether the subcaptions of Fig. 5 are okay. 


\title{
Influence of Silicon Layers on the Growth of ITO and AZO in Silicon Heterojunction Solar Cells
}

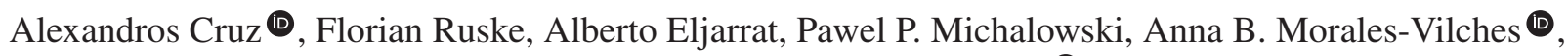

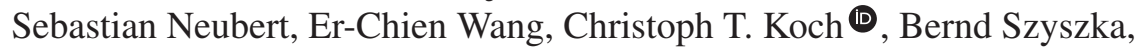 \\ Rutger Schlatmann $\mathbb{D}$, and Bernd Stannowski $\mathbb{D}$
}

\begin{abstract}
In this article, we report on the properties of indium tin oxide (ITO) deposited on thin-film silicon layers designed for the application as carrier selective contacts for silicon heterojunction (SHJ) solar cells. We find that ITO deposited on hydrogenated nanocrystalline silicon (nc-Si:H) layers presents a significant drop on electron mobility $\mu_{\mathrm{e}}$ in comparison to layers deposited on hydrogenated amorphous silicon films (a-Si:H). The nc-Si:H layers are not only found to exhibit a larger crystallinity than a-Si:H, but are also characterized by a considerably increased surface rms roughness. As we can see from transmission electron microscopy, this promotes the growth of smaller and fractured features in the initial stages of ITO growth. Furthermore, secondary ion mass spectrometry profiles show different penetration depths of hydrogen from the thin film silicon layers into the ITO, which might both influence ITO and device passivation properties. Comparing ITO to aluminum doped zinc oxide (AZO), we find that AZO can actually exhibit superior properties on nc-Si:H layers. We assess the impact of the modified ITO $R_{\text {sh }}$ on the series resistance $R_{s}$ of SHJ solar cells with $>23 \%$ efficiency for optimized devices. This behavior should be considered when designing solar cells with amorphous or nanocrystalline layers as carrier selective contacts.
\end{abstract}

Index Terms-Aluminum doped zinc oxide (AZO), indium tin oxide (ITO), secondary ion mass spectrometry (SIMS), series resistance, silicon heterojunction (SHJ), transmission electron microscopy (TEM), transparent conductive oxide (TCO).

Manuscript received August 29, 2019; revised November 1, 2019; accepted November 22, 2019. This work was supported in part by the German Ministry of Economic Affairs and Energy (BMWi) in the framework of the Dynasto (0324293B) and ProSelect (0324189C) projects. (Corresponding author: Alexandros Cruz.)

A. Cruz, A. B. Morales-Vilches, S. Neubert, E.-C. Wang, R. Schlatmann, and B. Stannowski are with the PVcomB, Helmholtz-Zentrum Berlin fur Materialien und Energie GmbH, 12489 Berlin, Germany (e-mail: alexandros.cruz@helmholtz-berlin.de; ana.morales_vilches@helmholtz-berlin. de; sebastian.neubert@helmholtz-berlin.de; er-chien.wang@helmholtz-berlin. de; rutger.schlatmann@helmholtz-berlin.de; bernd.stannowski@helmholtzberlin.de).

F. Ruske is with the Institute for Silicon Photovoltaics, Helmholtz-Zentrum Berlin fur Materialien und Energie GmbH, 14109 Berlin, Germany (e-mail: florian.ruske@helmholtz-berlin.de).

A. Eljarrat and C. T. Koch are with the Department of Physics, HumboldtUniversitat zu Berlin, 14109 Berlin, Germany (e-mail: aeljarrat@physik.huberlin.de; christoph.koch@hu-berlin.de).

P. P. Michalowski is with the Institute of Electronic Materials Technology, 01-919 Warszawa, Poland (e-mail: pawel.michalowski@itme.edu.pl).

B. Szyszka is with the Institute of High-Frequency and Semiconductor System Technologies, Technische Universitat Berlin, 10623 Berlin, Germany (e-mail: bernd.szyszka@tu-berlin.de).

Color versions of one or more of the figures in this article are available online at http://ieeexplore.ieee.org.

Digital Object Identifier 10.1109/JPHOTOV.2019.2957665

\section{INTRODUCTION}

$\mathbf{S}$ ILICON heterojunction (SHJ) solar cell technology is positioned as a strong candidate for mass production due to its high-efficiency potential and the lean manufacturing process consisting of only four main steps [1]. Record single-junction efficiencies for crystalline silicon (c-Si) based lab solar cells of $25.1 \%$ and $26.7 \%$ for two-side and all-back contacted devices, respectively, make this cell concept very attractive [2]-[4]. Recently, efficiencies above $24 \%$ have been reported for full-size SHJ solar cells processed on mass production systems [5], [6]. This solar cell concept achieves high open-circuit voltages $\left(V_{\text {oc }}\right)$ above $740 \mathrm{mV}$ through passivating selective contacts. Typically, a thin (3-5 nm) intrinsic hydrogenated amorphous silicon [(i)a-Si:H] layer is deposited for surface passivation on both sides of the silicon wafer followed by $\mathrm{p}$-doped and n-doped a-Si:H layers that act as carrier selective contacts for holes and electrons, respectively [7]. In recent years, hydrogenated nanocrystalline silicon (nc-Si:H) layers have been implemented as more conductive and transparent selective contact alternatives [8]-[12]. The lateral conductivity of such layers (and the Si bulk) is relatively low and a transparent conductive oxide (TCO) is needed to achieve a sufficiently low resistive lateral carrier transport to the metal-grid fingers.

Indium tin oxide (ITO) is a widely used TCO material for SHJ solar cell technology [13]-[16] whereas aluminum doped zinc oxide (AZO) is an interesting substitute due to the high abundance of $\mathrm{Zn}$ and the lower costs [17]-[19]. Interestingly, the optoelectrical properties of these TCOs can be strongly affected by the properties of the layers they are deposited on. In our solar cell devices, we systematically observe a higher sheet resistance $\left(R_{\mathrm{Sh}}\right)$ for ITO deposited on nc-Si:H layers than on a-Si:H. This is not the case for AZO.

Ritzau et al. [14] observed a strong increase of the carrier concentration $\left(N_{e}\right)$ in ITO deposited on p-doped a-Si:H upon thermal annealing whereas no $N_{e}$ increase was observed for ITO deposited on bare glass. This gave a strong indication that the ITO can be doped by hydrogen $(H)$ of underlying layers. Considering these findings, Haschke et al. [20] observed $R_{\mathrm{sh}}$ discrepancies between ITO deposited on glass, on (p)a-Si:H coated glass and on (p)nc-Si coated glass, which they explained with the same phenomenon.

In this article, we analyze electrical, structural, and chemical properties of ITO and AZO deposited on different thin-film 
TABLE I

THIN-FILM Si LAYERS USED AS SUBSTRATES FOR THE TCOS

\begin{tabular}{cccccc}
\hline \hline Name & $\begin{array}{c}\text { Thickness } \\
(\mathrm{nm})\end{array}$ & Type & Doping & $\begin{array}{c}F_{\mathrm{c}}^{\mathrm{Si}} \\
(\%)\end{array}$ & $\begin{array}{c}\text { RMS } \\
\text { roughness } \\
(\mathrm{nm})\end{array}$ \\
\hline $\mathrm{aSi}_{12}^{\mathrm{p}}$ & 12 & $\mathrm{a}-\mathrm{Si}: \mathrm{H}$ & (p) Boron & - & 0.9 \\
$\mathrm{aSi}_{12}^{\mathrm{n}}$ & 12 & $\mathrm{a}-\mathrm{Si}: \mathrm{H}$ & (n) phosphorous & - & 0.6 \\
$\mathrm{aSi}_{100}^{\mathrm{i}}$ & 100 & $\mathrm{a}-\mathrm{Si}: \mathrm{H}$ & (i) intrinsic & 0 & 0.5 \\
$\mathrm{ncSi}_{12}^{\mathrm{n}}$ & 12 & $\mathrm{nc}-\mathrm{Si}: \mathrm{H}$ & (n) phosphorous & - & 2.3 \\
$\mathrm{ncSi}_{12}^{\mathrm{p}}$ & 12 & $\mathrm{nc}-\mathrm{Si}: \mathrm{H}$ & (p) Boron & - & 1.9 \\
$\mathrm{ncSi}_{100}^{\mathrm{n}}$ & 100 & nc-Si:H & (n) phosphorous & 40 & 3.5 \\
$\mathrm{ncSi}_{100}^{\mathrm{i}}$ & 100 & nc-Si:H & (i) intrinsic & 80 & 9.8 \\
\hline \hline
\end{tabular}

silicon substrates. The aim is to elucidate the reasons behind the previously mentioned variations in TCO conductivity when implemented in devices. We observe that in the case of the ITO the electron mobility $\mu_{e}$ is strongly affected by the underlying $\mathrm{Si}$ layer. In contrast, the $N_{e}$ shows similar behavior independently of substrate type. We find that $\mu_{e}$ decreases with increased thinfilm silicon layer crystalline fraction $\left(\mathrm{F}_{\mathrm{c}}^{\mathrm{Si}}\right)$ that promotes a higher root mean square (rms) roughness of the substrate layer. We ascribe this $\mu_{e}$ decrease to increased grain boundary scattering due to decreased mean grain size $(L)$ and/or increased grain barrier trap density $\left(D_{t}\right)$. This behavior is of major relevance for the optimization of ITO for SHJ solar cells.

\section{EXPERIMENTAL}

\section{A. Layer Stacks Preparation and Characterization}

For the investigated material stacks, $1.1 \mathrm{~mm}$ thick Corning Eagle XG glasses were used as substrates. Intrinsic and doped thin-film silicon layers were deposited by plasma-enhanced chemical vapor deposition (PECVD) in an AKT1600 cluster tool from Applied Materials with a parallel electrode configuration operated at $13.56 \mathrm{MHz}$. To resemble SHJ solar cell-like grown thin-film silicon layers, a $5 \mathrm{~nm}$ (i)a-Si:H was initially deposited on the glass substrates. On top of the (i)a-Si:H layer, thin-film silicon layers as given in Table I were deposited. A thickness of 12 $\mathrm{nm}$ was chosen since it is relevant for SHJ solar cell technology and $100 \mathrm{~nm}$ thick layers were investigated to compare layers that have a further developed structure. Crystalline fraction $F_{\mathrm{c}}^{\mathrm{Si}}$ of the $100 \mathrm{~nm}$ thick layers was derived from Raman spectroscopy as described in [21] with $F_{c}^{\mathrm{Si}}=I_{c} /\left(I_{a}+m I_{c}\right)$, where $I_{a}$ is the Raman peak intensity associated with the amorphous phase, $I_{c}$ is the intensity associated with the crystalline phase and $m$ is a corrective factor which was set to 1 in this article.

The rms roughness of the layers was determined via atomic force microscopy.

TCO layers were deposited in an in-line dc magnetron sputtering system from Leybold Optics (A600V7). ITO layers were sputtered from a $95 \mathrm{wt} \% \mathrm{In} 2 \mathrm{O} 3$ and $5 \mathrm{wt} \% \mathrm{SnO} 2$ ceramic tube target and the AZO films were sputtered from a $99 \mathrm{wt} \% \mathrm{ZnO}$ and $1 \mathrm{wt} \% \mathrm{Al}_{2} \mathrm{O}_{3}$ ceramic tube target. Both TCOs were deposited at an approximate substrate temperature of $140 \pm 20^{\circ} \mathrm{C}$ with oxygen flow ratios $r\left(O_{2}\right)=q\left(O_{2}\right) / q\left(A r+O_{2}\right)$ of $1.6 \%$ and $0.2 \%$, respectively. The samples were annealed on a hot-plate at a temperature of $210{ }^{\circ} \mathrm{C}$ for $15 \mathrm{~min}$ in the ambient atmosphere as it is also done for the curing process after silver-grid screenprinting used for our solar cells. A TCO thickness of $110 \mathrm{~nm}$ on a flat substrate was chosen since this results in a $75 \pm 10 \mathrm{~nm}$ layer perpendicular to the pyramid surfaces on a textured wafer, which is required for ideal anti-reflection properties on solar cell devices.

The TCO layers electron mobility, $\mu_{e}$, and concentration, $N_{e}$, were determined by Hall measurements with an Ecopia HMS 3000 system applying the van der Pauw method. Three samples were prepared for Hall measurements for each variation. The mean values and their average deviation are indicated in the graph. Scanning electron microscopy (SEM) was carried out in a MERLIN system from Zeiss on the layers to study and compare their surface morphology. Furthermore, secondary ion mass spectroscopy (SIMS) measurements were carried out on selected samples. SIMS measurements were performed employing the CAMECA SC Ultra instrument under ultra-high vacuum, usually of $4 \times 10^{-10} \mathrm{mbar}$. Enough depth resolution was obtained for negative ions detection mode by using a low impact energy of $100 \mathrm{eV}$ for a Cs + primary beam scanned over $250 \times 250 \mu \mathrm{m}^{2}$. The extremely low impact energy of primary ions $(100 \mathrm{eV})$ not only ensure a desired depth resolution but almost completely eliminate the mixing effect and thus most signals have very sharp interfaces. Thus, the hydrogen decay curve can be attributed to actual diffusion and not to any potential SIMS-related artifacts [22], [23]. The layer stacks for SIMS measurements were prepared on $200 \mu \mathrm{m}$ thick polished Czochralski wafers with the same layer stacks as on glass. P-doped wafers were used for (n)nc-Si:H samples and n-doped wafers for (p)a-Si:H samples. This in order to electrically decouple the thin-film layers from the wafer and measure Hall parameters.

Transmission electron microscopy (TEM) was carried out using a Jeol JEM2200FS equipped with a Nanomegas ASTAR system. Samples were prepared using a focused ion beam (FIB). High-resolution and dark/bright-field imaging observation in conjunction with scanning nano-beam electron diffraction (NBED) acquisition were employed. The NBED datasets contain $128 \times 128$ diffraction patterns, acquired at positions with a separation of $1.5 \mathrm{~nm}$ along both lateral dimensions. The NBED datasets were calibrated using the intense central spot as a reference, and virtual bright- and dark-field images were obtained using a circular detector mask.

\section{B. Solar Cells Preparation and Characterization}

Solar cells were prepared using n-type Czochralski (CZ) silicon wafers (c-Si) with $5 \Omega \mathrm{cm}$ resistivity. The as-cut wafers were wet-chemically etched to eliminate the sawing damage. Its surfaces were then textured in $\mathrm{KOH}$ to obtain random pyramids with heights in the range of $1-3 \mu \mathrm{m}$ with $<111>$ oriented facets and resulting in $125 \mu \mathrm{m}$ thick wafers. After RCA cleaning and a dip in a $1 \%$ diluted hydrofluoric acid solution, intrinsic and doped silicon layers were deposited in the PECVD reactor system as described in Section II-A. An i/p a-Si:H stack was deposited on the rear-side to form the hole contact (rear-junction). At the front side an electron contact was formed by depositing an (i)a-Si:H 


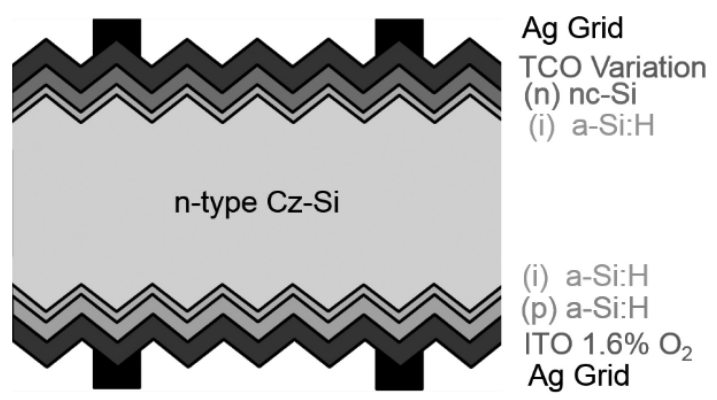

Fig. 1. Standard processed rear-junction SHJ solar cell schematic cross section.

with an (n)nc-Si:H layer on top. The solar cells were prepared by varying the front TCO layers as described in Fig. 4 . The back TCO was made with the $1.6 \% \mathrm{O}_{2}$ partial flow ITO with the process parameters as described in Section II-A. The TCO layers were sputtered through aligned shadow masks on both sides of the wafer to define $144-\mathrm{cm}^{2}$ sized cells and three transfer length method (TLM) structures per wafer.

A silver grid with a 1670 and $800 \mu \mathrm{m}$ finger-pitch was screenprinted at the front and back of the solar cells, respectively. The grid was cured at $210{ }^{\circ} \mathrm{C}$ for 15 min on a hot-plate under atmospheric conditions. Fig. 1 shows the schematic cross section of the described rear-junction SHJ solar cell.

The solar cells were characterized using current densityvoltage $(J-V)$ measurements in the dark and under an AM1.5G spectrum at standard test conditions in a Wacom WXS-155S-L2 dual source class $\mathrm{AAA}+$ sun simulator. Resistance measurements were made on the TLM structures to calculate the TCO sheet resistance $\left(R_{\mathrm{sh}}\right)$ on devices. To derive the TCO $R_{\mathrm{sh}}$ from an (n) wafer/(i)a-Si:H/(n)nc-Si:H stack from TLM structures we used a parallel resistance model as proposed by Bivour et al. [5]. According to this model $R_{\mathrm{sh}, \mathrm{TCO}}$ can be determined from

$$
\mathrm{R}_{\text {ShTCO }}=1 /\left(\frac{1}{R_{\text {shTLM }}}-\frac{1}{R_{\text {shWafer }}}\right)
$$

with $R_{\mathrm{ShTCO}}$ being the TCO $R_{\mathrm{sh}}, R_{\mathrm{Sh}}$ TLM the $R_{\mathrm{sh}}$ measured via TLM structures, and $R_{\mathrm{shWafer}}$ the $R_{\mathrm{sh}}$ of the wafer. The latter was obtained from quasi-steady state photo conductance decay measurements for each sample. The average wafer $R_{\mathrm{sh}}$ was $380 \pm 10 \Omega$. The effect of contact resistivity is neglected and we assume the value is low enough and permits current flow into the wafer. $R_{s}$ values of the solar cells were determined from the dark to light $J-V$ curve comparison according to [24].

\section{RESULTS AND DISCUSSION}

\section{A. Thin-Film Silicon Layer Properties}

In Table I, the different thin film silicon layers investigated are presented. The layer names indicate the layer type (a-Si or nc-Si), the doping type (i, p, or n) as superscript and the layer thickness (12 or $100 \mathrm{~nm}$ ) as subscript. The properties presented in Table I show that the $\mathrm{F}_{\mathrm{c}}^{\mathrm{Si}}$ of the layers increases from $0 \%$ for an amorphous layer, $\mathrm{aSi}_{100}^{\mathrm{i}}$, to $80 \%$ for the layer with highest $\mathrm{F}_{c}^{\mathrm{Si}}$, i.e., $\mathrm{ncSi}_{100}^{i}$. For the standard (n)nc-Si:H layer used in the

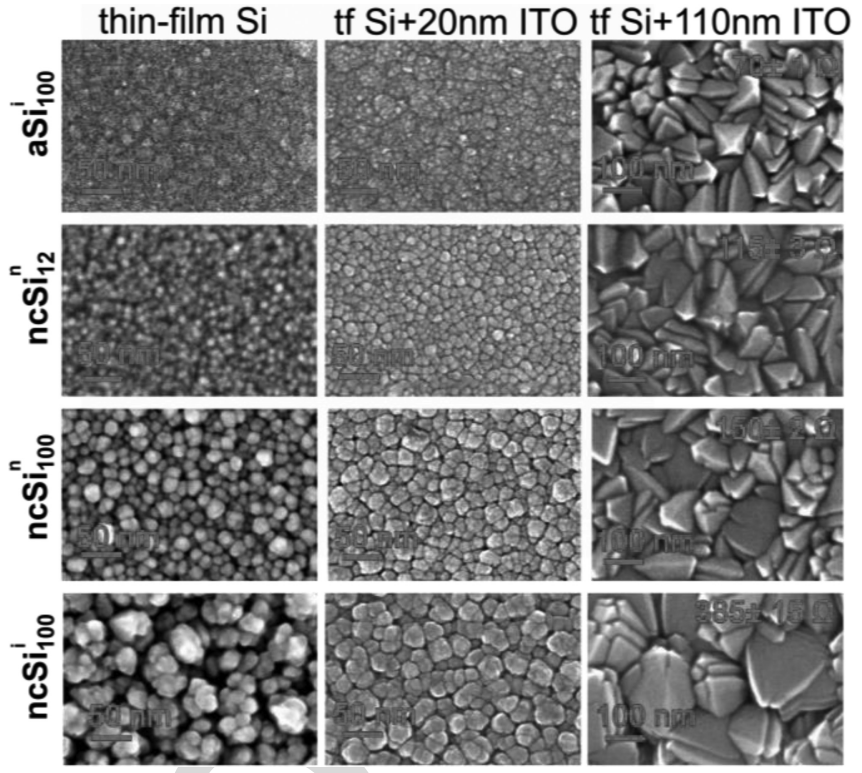

Fig. 2. SEM micrographs of thin-film silicon layers on glass (first column), with $20 \mathrm{~nm}$ ITO (second column) and with $110 \mathrm{~nm}$ ITO (third column) layers on top. The thin-film silicon layer substrate type is indicated at the left of the first column, detailed properties of the layers can be found in Table I. Length scales are indicated for each image. Sheet resistance values measured on the $110 \mathrm{~nm}$ ITO layers are indicated in the third column.

solar cells, $\mathrm{ncSi}_{12}^{\mathrm{n}}$, no Raman spectrum could be measured since it is device relevantly thin at $12 \mathrm{~nm}$. However, it is well known from the literature that the $\mathrm{F}_{c}^{\mathrm{Si}}$ of the nc-Si:H layers will lower with decreased film thickness [8], [9], [19], [20]. Fioretti et al. recently reported that the PECVD deposited p-doped nc-Si:H layers, at the cell level, can increase its crystallinity when reducing the deposition temperature, from 200 to $125^{\circ} \mathrm{C}$ [12]. However, this trend was not followed in the case of the n-doped nc-Si:H layers that are the main focus of our article. Hence, we can assume that $\mathrm{ncSi}_{12}^{n}$ and $\mathrm{ncSi}_{12}^{p}$ layers have an $\mathrm{F}_{c}^{\mathrm{Si}}$ between $0 \%$ and $40 \%$.

We see a correlation of the $\mathrm{F}_{c}^{\mathrm{Si}}$ and the rms roughness. The rms roughness steadily increases with layer $\mathrm{F}_{c}^{\mathrm{Si}}$ from $0.5 \mathrm{~nm}$ for $\mathrm{aSi}_{100}^{i}$ to $9.8 \mathrm{~nm}$ for $\mathrm{ncSi}_{100}^{i}$. Furthermore, SEM micrographs shown in the first column of Fig. 2 reveal that the $\mathrm{F}_{c}^{\mathrm{Si}}$ and the rms roughness correlate with the mean grain size of the films as well. It is worth mentioning that the surface topographies did not show any noticeable change between as deposited and annealed state.

The SEM micrographs in the second column of Fig. 2 show corresponding substrates with a $20 \mathrm{~nm}$ ITO layer deposited on top. These images clearly show that at its initial growth stage the ITO adopts a similar morphology as the underlying silicon layers. However, when analyzing the surface morphology of the $110 \mathrm{~nm}$ ITO layers seen in column 3 of Fig. 2, we see that the ITO layers reconfigure their structure and acquire a sharp polycrystalline grain shape, which is a typical morphology for ITO sputtered under conditions as described in Section II-A [25]. The $R_{\mathrm{sh}}$ values observed in Fig. 2 for the $110 \mathrm{~nm}$ ITO layers show the discrepancies of the conductivity of these layers depending 


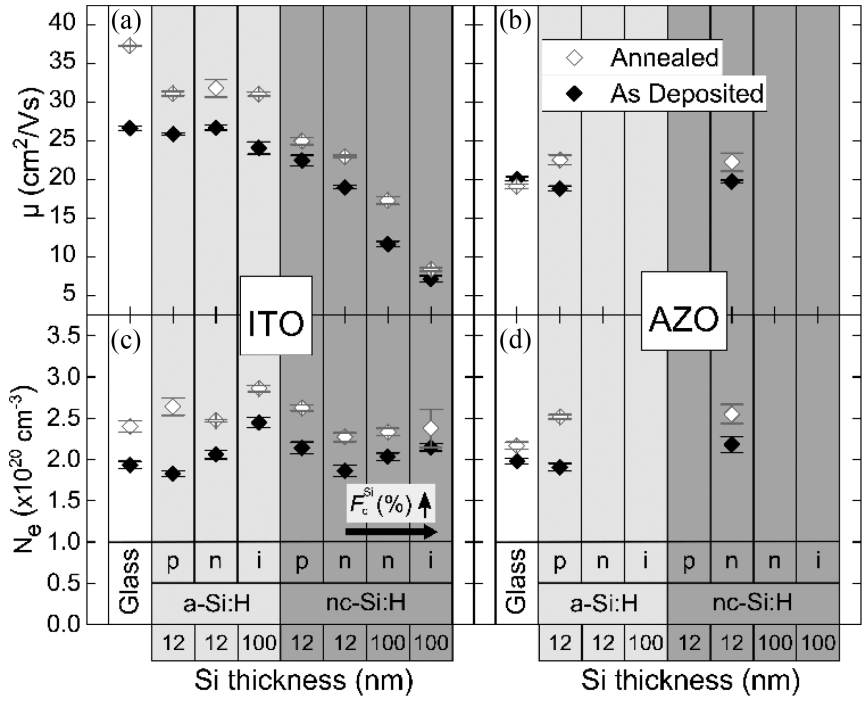

Fig. 3. Hall electron mobility $\mu_{e}$ of $105 \pm 10 \mathrm{~nm}$ thick (a) ITO and (b) AZO layers deposited on bare and coated glass with varied thin-film silicon layers and Hall carrier concentration $N_{e}$ of same (c) ITO and (d) AZO layers. Doping and layer type are indicated on top of the thin film silicon thicknesses. The arrow indicates the increase of crystallinity fraction $\mathrm{F}_{\mathrm{C}}^{\mathrm{Si}}$ for the corresponding thin film silicon layers. on the underlying substrate. ITO on $\mathrm{aSi}_{100}^{i}$ exhibits $R_{\mathrm{sh}}=70 \pm$ $1 \Omega$ whereas ITO on $\mathrm{ncSi}_{100}^{i}$ has $R_{\mathrm{sh}}=385 \pm 15 \Omega$.

On the thick nc-Si ncSi ${ }_{100}^{i}$ layer, the ITO presents clearly larger crystals as compared to the thick amorphous as well as both 12-nm thin nc-Si under layers. Differences between TCO layers on thin $\mathrm{aSi}_{12}^{p}$ and $\mathrm{ncSi}_{12}^{n}$ layers are further investigated with TEM microscopy in Section III-C.

\section{B. TCO Electrical Properties}

The analyzed TCO layers were designed for the application on SHJ solar cells. Therefore, the process parameters were optimized for the highest $\mu_{e}$ possible at an $N_{e}$ that has low free carrier absorption typically around a value of $2 \times 10^{20} \mathrm{~cm}^{-3}$ [26].

For both materials, ITO and AZO, the concentration of carriers is determined by the level of extrinsic doping and intrinsic acceptors as oxygen interstitials or metal vacancies. The formation of the acceptor type defects is strongly promoted by the addition of oxygen to the growth process [27]. Hence, it is possible to control the optoelectric properties through adjustment of the oxygen partial pressure during deposition [28], [29].

In this article, the oxygen flow rate was chosen to lead to the desired $N_{e}$ of $2 \times 10^{20} \mathrm{~cm}^{-3}$ on glass substrates and the deposition conditions were maintained for all studied samples. As a result, the $N_{e}$ for films grown on the various substrates under investigation are very similar. From Fig. 3(c) and (d), we can see that $N_{e}$ remains in a range of $2.1 \pm 0.3 \times 10^{20} \mathrm{~cm}^{-3}$ for layers in as-deposited state and increases to $2.4 \pm 0.3 \times$ $10^{20} \mathrm{~cm}^{-3}$ after annealing for both ITO and AZO.

As we see from Fig. 3(a), ITO grown on layer $\mathrm{ncSi}_{12}^{n}$ has a lower $\mu_{e}$ in comparison to the one on $\mathrm{aSi}_{12}^{p}$. In contrast, in Fig. 3(b), the AZO shows the same $\mu_{e}$ on $\mathrm{aSi}_{12}^{p}$ and $\mathrm{ncSi}_{12}^{n}$.

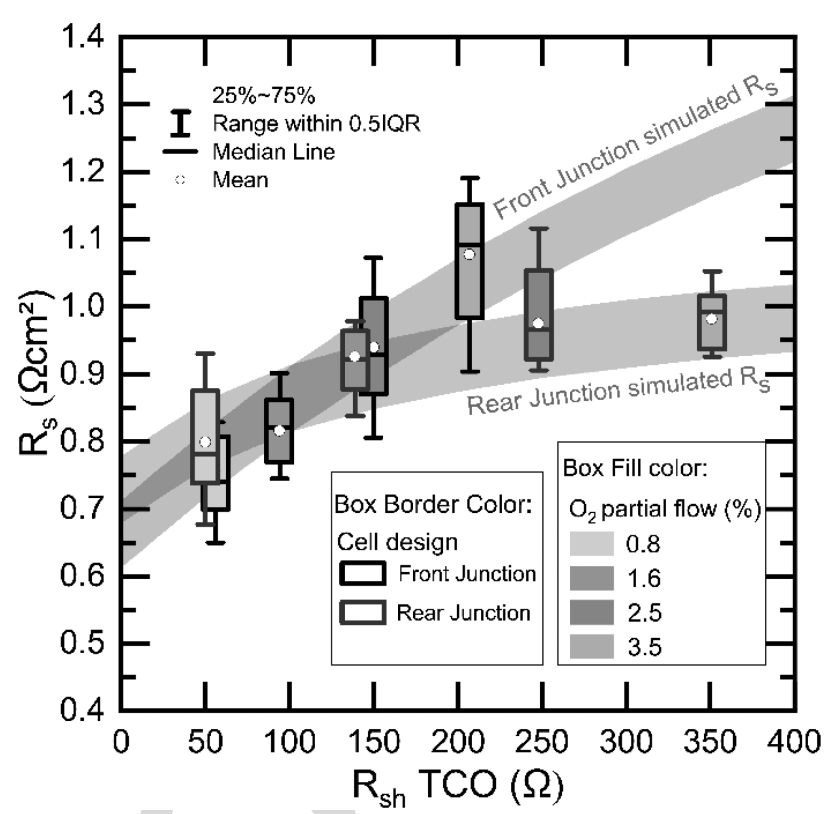

Fig. 4. Rear- and front-junction SHJ solar cells series resistance $R_{s}$ versus ITO sheet resistance $R_{\mathrm{sh}}$. The front contact ITO $R_{\mathrm{sh}}$ was varied through the $\mathrm{O}_{2}$ process partial flow. The back contact is identical for all cells. Simulated $R_{\mathrm{S}}$ versus $R_{\mathrm{Sh}}$ TCO curves for rear- and front-junction devices after [30] are included. The simulation curves include an error of $\pm 0.05 \Omega \mathrm{cm}^{2}$. The boxplots show values of 28 cells in two wafers per box.

As a result, $\mu_{e}$ is around $22 \mathrm{~cm}^{2} / \mathrm{Vs}$ for both ITO and AZO when deposited on $\mathrm{ncSi}_{12}^{n}$. The ITO presents an even lower $\mu_{e}$ of $8.4 \pm 0.2 \mathrm{~cm}^{2} / \mathrm{Vs}$ when grown on the $\mathrm{ncSi}_{100}^{i}$ layer. This behavior shows a clear correlation of a decreased $\mu_{e}$ of the ITO with higher $\mathrm{F}_{c}^{\mathrm{Si}}$, rms surface roughness and grain size of the previously described silicon underlying layers.

To investigate whether the $\mu_{e}$ differences are related to the doping type of the thin silicon films, we compare ITO layers deposited on intrinsic $\left(\mathrm{aSi}_{100}^{i}\right)$, phosphorous doped $\left(\mathrm{aSi}_{12}^{n}\right)$, and boron-doped $\left(\mathrm{aSi}_{12}^{p}\right)$ a-Si:H with its counterparts on doped nc$\mathrm{Si}: H$ layers $\left(\mathrm{ncSi}_{100}^{i}, \mathrm{ncSi}_{12}^{p}, \mathrm{ncSi}_{12}^{n}\right.$, respectively. From Fig. 3(a), we confirm that the ITO presents in all cases lower $\mu_{e}$ when deposited on nc-Si:H than on a-Si:H independently of the type of doping.

The same behavior was observed in finished solar cells, namely a conductivity decrease of ITO layers grown on nc-Si as compared to a-Si contact layers. To demonstrate this, in Fig. 4, we show the result of different front ITO $R_{\mathrm{sh}}$ by oxygen-flow variation (the back TCO contact is the same for all cells) and its impact on device series resistance $R_{s}$ for front-junction and rear-junction solar cells. The results show that the front ITO deposited with the same process conditions on (n)nc-Si:H (rearjunction cells) generally presents higher $R_{\mathrm{sh}}$ than its counterparts deposited on (p)a-Si:H layers (front-junction cells). The ITO $R_{\mathrm{sh}}$ differences have a direct impact on the solar cells $R_{s}$ and hence on its Fill-Factor $(F F)$ depending on the solar cell design [30]. After optimization, solar cells with ITO $\left(J_{\mathrm{sc}}=39.0 \mathrm{~mA} / \mathrm{cm}^{2}\right.$; $\left.V_{\mathrm{oc}}=742 \mathrm{mV} ; F F=81.1 \%\right)$ and $\mathrm{AZO}\left(J_{\mathrm{sc}}=39.1 \mathrm{~mA} / \mathrm{cm}^{2}\right.$; $\left.V_{\mathrm{oc}}=741 \mathrm{mV} ; F F=81.2 \%\right)$ front electrodes both lead to the same certified (ISFH CalTeC) efficiency of $23.5 \%$. Interestingly,
269 270 271 272 273 
(p)a-Si:H-12 nm
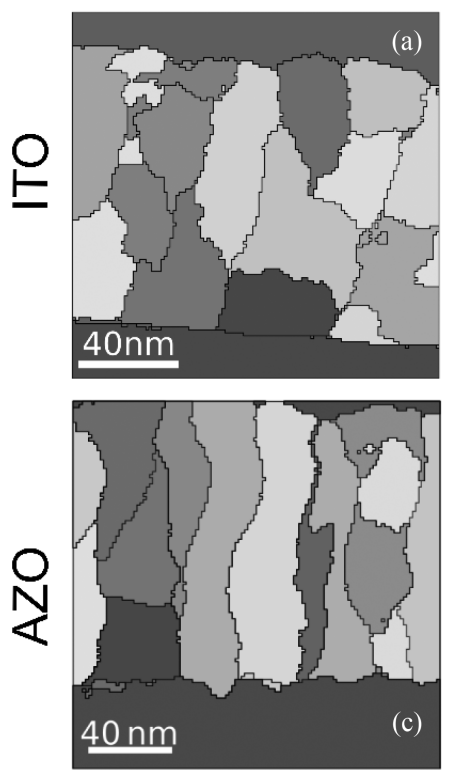

(n)nc-Si:H- 12 nm
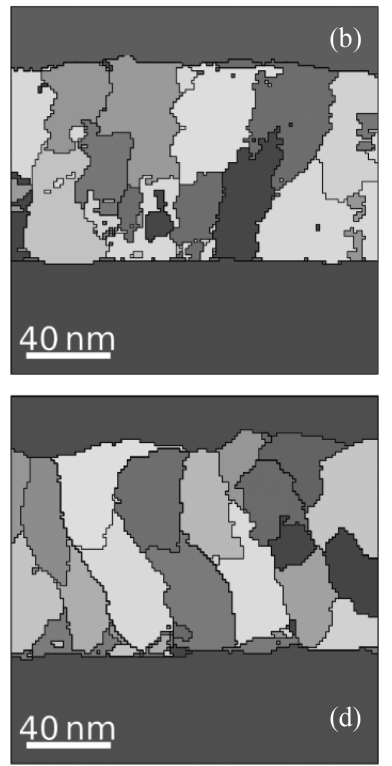

Fig. 5. Scanning NBED acquisitions of $105 \pm 10 \mathrm{~nm}$ ITO (a), (b) and AZO (c), (d) on (p)a-Si:H and (n)nc-Si:H coated c-Si wafers, obtained from TEM imaging observations. The samples are prepared on $200-\mu$ m-thick Czochralski c-Si wafers positioned at the bottom in the images. The images show only crystals from the TCO materials.

the ITO $R_{\mathrm{sh}}$ discrepancy increases for the higher $\mathrm{O}_{2}$ partial flow ITO. This effect was also observed by Haschke et al. [20] for ITO deposited on (p)a-Si:H and on (p)nc-Si:H coated glass. The analysis in this article is based on flat substrates. Nonetheless, the influence of textured substrates on the studied effect is worth of further investigation.

\section{Structural Properties}

Fig. 5 shows the microstructure of the ITO and AZO obtained by a cluster analysis of the scanning NBED data that was acquired in the TEM measurements. Fig. 5(a) and (b) shows the polycrystalline ITO layers deposited on $\mathrm{aSi}_{12}^{p}$ and $\mathrm{ncSi}_{12}^{n}$ layers, respectively. It is noticeable that the ITO layer on $\mathrm{ncSi}_{12}^{n}$ shows smaller and more fractured domains in its initial growth stages. After this initial growing stage, the layer reconfigures its microstructure and resembles the shapes of the ITO grains on $\mathrm{aSi}_{12}^{p}$. This is consistent with the top view SEM micrographs of the 110-nm ITO layers shown in Fig. 2. We can observe that the average grain size of the layer on $\mathrm{ncSi}_{12}^{n}$ is smaller than that on $\mathrm{aSi}_{12}^{p}$. Furthermore, the grain boundaries for the ITO on $\mathrm{ncSi}_{12}^{n}$ are more irregular.

On the other hand, the AZO is less affected by the underlying layer as seen from Fig. 5(c) and (d). The typical columnar growth for this material [31] can be seen in the images. That correlates well with the unchanged $\mu_{e}$ of the AZO.

In Section III-E, the behavior of $\mu_{e}$ is discussed in detail considering the findings from the different characterization methods.

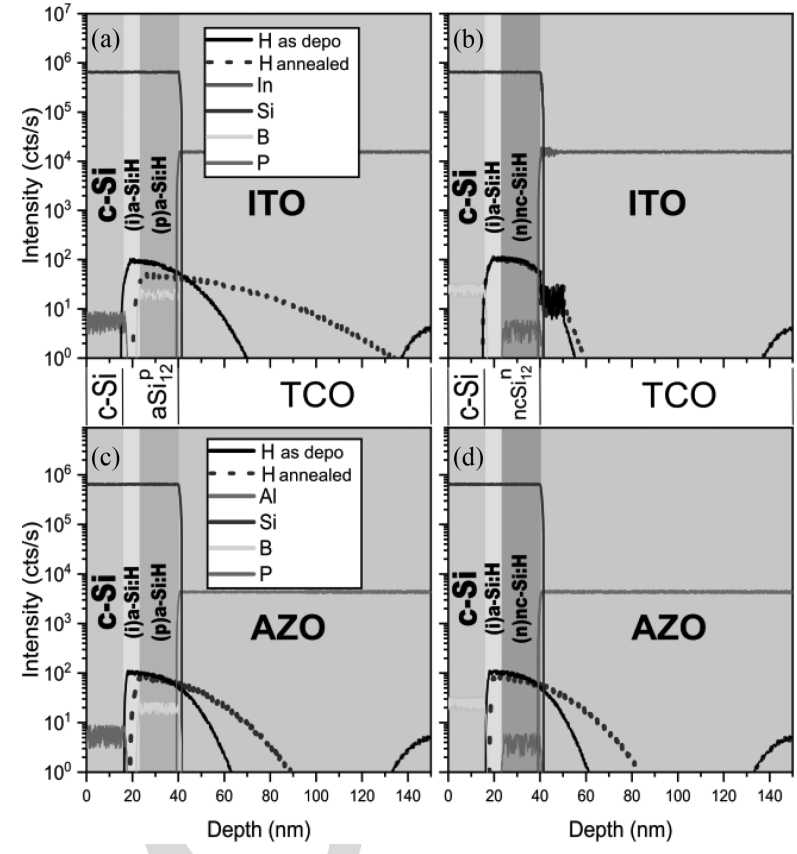

Fig. 6. SIMS measurements of ITO on (a) (i)a-Si:H / (p)a-Si:H ( $\mathrm{aSi}_{12}^{\mathrm{p}}$ ) layer and (b) (i)a-Si:H / (n)nc-Si:H (ncSin ${ }_{12}^{n}$ ) layer. As well as AZO on (c) (i)a-Si:H/ (p)a-Si:H ( $\mathrm{aSi}_{12}^{\mathrm{p}}$ ) layer and (d) (i)a-Si:H / (n)nc-Si:H ( $\left.\mathrm{ncSi}_{12}^{\mathrm{n}}\right)$ layer. Indium (In), Aluminum (Al), Silicon ( $\mathrm{Si}$ ), Boron (B), and Phosphorous (P) signals on as deposited and annealed state overlap almost identically within noise error. Hydrogen $(\mathrm{H})$ straight lines are for as deposited state and dashed lines for annealed state.

\section{Role of Hydrogen Diffusion}

From previous studies, it is known that hydrogen diffusion into TCO materials can play a significant role in their electrical properties [14], [32], [33]. To understand the role of diffused hydrogen in the TCO materials SIMS measurements were carried out.

Fig. 6 shows SIMS measurements of ITO and AZO grown on $\mathrm{aSi}_{12}^{p}$ and $\mathrm{ncSi}_{12}^{n}$ layers in as deposited state and after annealing. The annealing process has a noticeable effect on the $H$ diffusion. All other elements remain almost unchanged.

Interestingly, we observe a clear difference in $H$ penetration depth for ITO depending on the underlying Si layer. For ITO grown on a $\mathrm{ncSi}_{12}^{n}$ type layer, a $H$ signal is detected until a depth of approx. $55 \mathrm{~nm}$, whereas the layer deposited on the $\mathrm{aSi}_{12}^{p}$ type layer presents a penetration depth of $70 \mathrm{~nm}$ in as-deposited state as we can see from Fig. 6(a) and (b). After annealing, the $H$ further diffuses into the layer and increases its depth to up to $130 \mathrm{~nm}$ for $\mathrm{aSi}_{12}^{p}$ but only to $60 \mathrm{~nm}$ for $\mathrm{ncSi}_{12}^{n}$. On the other hand, the AZO shows very similar $H$ penetration depths independently of the layer on which it is deposited. The depths are of 61 and $62 \mathrm{~nm}$ in as deposited state and these increase to 82 and $87 \mathrm{~nm}$ after the annealing step for the $\mathrm{ncSi}_{12}^{n}$ and $\mathrm{aSi}_{12}^{p}$ substrates, respectively. Another effect worth mentioning is that samples with $\mathrm{aSi}_{12}^{p}$ layers exhibit a stronger $H$ depletion from the (i)a-Si:H/c-Si interface as seen in the SIMS profiles after annealing. Ritzau et al. [14] already stressed out, that a boron (p) doped a-Si:H layer allows more effusion of hydrogen through 
decrease of its activation energy in comparison to a phosphorous (n) doped layer. This effect promotes the extraction of hydrogen from the (i)a-Si:H layer and might be a reason for degradation of the passivating effect of dangling bonds at the (i)a-Si:H/c-Si interface [34]. Interestingly the ITO layer grown on $\mathrm{ncSi}_{12}^{n}$ that obstructs the diffusion into the TCO clearly maintains the highest amount of hydrogen at the $\mathrm{c}-\mathrm{Si} /(\mathrm{n}) \mathrm{nc}-\mathrm{Si}: \mathrm{H}$ interface, which might be beneficial for passivation purposes.

\section{E. Discussion: Electron Mobility Behavior}

In order to understand the differences in $\mu_{e}$ for the ITO layers grown on different substrates it is important to consider the various scattering processes limiting the $\mu_{e}$ in TCO layers. In the past years, authors have made considerable efforts to explain the $\mu_{e}$ limitation in both AZO and ITO [35], [36].

The maximum $\mu_{e}$ achievable for a given carrier concentration is only limited by phonon scattering and ionized impurity scattering. For ITO with a carrier concentration of $2 \times 10^{20} \mathrm{~cm}^{-3}$ carriers, Preissler et al. calculated an $\mu_{e}$ of approx. $70 \mathrm{~cm}^{2} / \mathrm{Vs}$, which is by far higher than our values. Neglecting the unknown influence of possible neutral impurity scattering and dislocation scattering, the main reasons for this deviation can be compensation [35] and grain boundary scattering [37], [38].

Compensation not only influences $\mu_{e}$, but also determines the $N_{e}$ in the films. Seeing that our films exhibit very similar carrier concentrations regardless of the substrate, we conclude that the compensation is mainly determined by the growth conditions rather than the substrate and its influence on the structure of the TCO layers. Hence, we can assume that compensation is similar for all samples and only minor changes might occur during annealing. This context leaves the grain boundary scattering as the main possible mechanism influencing the variation of $\mu_{e}$. Equation (2) shows the expression for effective mobility $\mu_{\text {eff }}$ developed by Seto [39]

$$
\mu_{\mathrm{eff}}=\frac{\mathrm{eL}}{\sqrt{2 \pi \mathrm{m}^{*} \mathrm{kT}}} \exp \left(-\frac{\mathrm{E}_{b}}{\mathrm{kT}}\right)
$$

where $L$ is the grain size, $m *$ is the electron effective mass, $E_{b}$ is the energetic barrier height at the grain boundary, $T$ the sample temperature, and $e$ and $k$ are the elementary charge and the Boltzmann constant, respectively. From (2), we see that the grain size affects the material $\mu_{\text {eff }}$ linearly. Hence, the smaller fractured grain features seen on the ITO deposited on $\mathrm{ncSi}_{12}^{n}$ in comparison to $\mathrm{aSi}_{12}^{p}$ layers can partially explain the diminished $\mu_{e}$ effect (see Fig. 5). A further effect to be considered is the influence of the energetic barrier $E_{b}$. Depending on the grain size $L$, the carrier concentration $N_{e}$ and the trap density at grain boundaries $D_{t}$, two expressions for the barrier height $E_{b}$ are applicable [37]

$$
\begin{aligned}
\mathrm{E}_{b}=\frac{\mathrm{e}^{2} \mathrm{D}_{t}^{2}}{8 \varepsilon \varepsilon_{0} \mathrm{~N}_{e}} & \text { for } \mathrm{LN}_{e}>\mathrm{D}_{t} \\
\mathrm{E}_{b}=\frac{\mathrm{e}^{2} \mathrm{~L}^{2} \mathrm{~N}_{e}}{8 \varepsilon \varepsilon_{0}} & \text { for } \mathrm{LN}_{e}<\mathrm{D}_{t}
\end{aligned}
$$

where $\varepsilon \varepsilon_{0}$ is the static dielectric constant.

Typical $D_{t}$ values for the TCO layers investigated here lie between $1 \times 10^{12}$ and $3 \times 10^{13} \mathrm{~cm}^{-2}$ [14], [37]. Thus, even for a very small mean $L$ value of $5 \mathrm{~nm}$, we have $L N_{e}>D_{t}$. Hence, $D_{t}$ is dominating the $E_{b}$ height according to (2a).

Under this circumstances, an increased $D_{t}$ at grain boundaries can be a further reason for decreased $\mu_{e}$ of the ITO layers on nc-Si:H.

From the measured SIMS profiles shown in Fig. 6, we can conclude that in none of the studied cases boron or phosphorous diffuses into the TCO layers. Hence, the diffusion of these elements is not a source of additional scattering impurities and the effect of lowered $\mu_{e}$ is independent of these dopants as it was already concluded from Fig. 3. A further effect that can have an impact on the $\mu_{e}$ of the layers is the diffusion of hydrogen into the TCOs coming from the hydrogenated thin-film silicon layers. We see from the SIMS profiles in Fig. 6 that the ITO receives less hydrogen from a $\mathrm{ncSi}_{12}^{n}$ layer. In contrast, the hydrogen penetrates deeper into the ITO layer grown on $\mathrm{aSi}_{12}^{p}$. We observe, however, that both the ITO layers on $\mathrm{aSi}_{12}^{p}$ and $n c \mathrm{Si}_{12}^{n}$ show an increase of $\mu_{e}$ upon annealing, so the potential influence of hydrogen diffusion remains unclear. In the case of the AZO, however, the layers present very similar hydrogen profiles, which are consistent with the almost equal $\mu_{e}$ that both layers show.

A clarification of the phenomena would require determination of the potential barriers from temperature-dependent Hall measurements, which are outside the scope of this article.

\section{CONCLUSION}

ITO deposited on nc-Si:H presents lower $\mu_{e}$ in comparison to same layers deposited on a-Si:H. This is related to an increased RMS roughness of the nc-Si:H correlating with thin-film silicon crystalline fraction and increased grain size. We find from TEM measurements that a surface with increased RMS roughness promotes the growth of smaller fractured grain features of the ITO at initial growth stages. In this context, possible explanations for the decreased $\mu_{e}$ are the decreased ITO mean grain size or an increase of the trap density at the materials' grain boundaries. Furthermore, we observe a lower hydrogen penetration depth for ITO layers grown on nc-Si than on a-Si as observed in SIMS profiles.

On the contrary, the AZO presents almost identical $\mu_{e}$ when deposited on nc-Si:H and a-Si:H which is consistent with the similarity in structural properties observed from TEM and diffusion profiles measured with SIMS.

ITO grown on an n-doped nc-Si:H layer clearly shows lesser out-diffusion of hydrogen from the c-Si/(i)a-Si:H interface as compared to the ITO grown on p-doped a-Si:H. The impact of this behavior on device passivation properties is relevant for further investigation.

The previously described phenomena should be considered during the development of carrier selective contacts for SHJ solar cells.

\section{ACKNOWLEDGMENT}

We would like to thank the coworkers at HZB for their support: K. Mayer-Stillrich and M. Hartig for sputtering depositions, M. Zelt and T. Henschel for support with PECVD, H. Rhein for 
screen-printing processing, M. Setzchen for device characterization and H. Kropf for FIB sample preparation, and K. Mack for Raman spectroscopy measurements. A. Cruz gratefully acknowledges the scholarship support from the Mexican National Council for Science and Technology (CONACYT).

\section{REFERENCES}

[1] J. Haschke, O. Dupré, M. Boccard, and C. Ballif, "Silicon heterojunction solar cells: Recent technological development and practical aspects - From lab to industry," Sol. Energy Mater. Sol. Cells, vol. 187, pp. 140-153, Dec. 2018.

[2] K. Yoshikawa et al., "Silicon heterojunction solar cell with interdigitated back contacts for a photoconversion efficiency over 26\%," Nat. Energy, vol. 2, no. 5, May 2017, Art. no. 17032.

[3] D. Adachi, J. L. Hernández, and K. Yamamoto, "Impact of carrier recombination on fill factor for large area heterojunction crystalline silicon solar cell with 25.1\% efficiency," Appl. Phys. Lett., vol. 107, no. 23, p. 233506, Dec. 2015.

[4] M. A. Green et al., "Solar cell efficiency tables (Version 53)," Prog. Photovolt. Res. Appl., vol. 27, no. 1, pp. 3-12, 2019.

[5] J. Zhao et al., " $>24 \%$ silicon heterojunction solar cells on meyer burger's on mass production tools and how wafer material impacts cell parameters," in Proc. IEEE 7th World Conf. Photovolt. Energy Convers. (A Joint Conf. 45th IEEE PVSC, 28th PVSEC 34th EU PVSEC), 2018, pp. 1514-1519.

[6] "Hanergy sets new efficiency record for heterojunction module," [Online]. Available: https://www.pv-magazine.com/2019/08/08/hanergy-setsnew-efficiency-record-for-heterojunction-module/. Accessed on Aug. 22, 2019.

[7] S. De Wolf, A. Descoeudres, Z. C. Holman, and C. Ballif, "High-efficiency silicon heterojunction solar cells: A review," Green, vol. 2, no. 1, pp. 7-24, 2012.

[8] A. B. Morales-Vilches, L. Mazzarella, M. Hendrichs, L. Korte, and B. Stannowski, "Nanocrystalline vs. amorphous n-type silicon front surface field layers in silicon heterojunction solar cells: Role of thickness and oxygen content," in Proc. EUPVSEC, 2017, pp. 715-719.

[9] P. Roca i Cabarrocas, N. Layadi, T. Heitz, B. Drévillon, and I. Solomon, "Substrate selectivity in the formation of microcrystalline silicon: Mechanisms and technological consequences," Appl. Phys. Lett., vol. 66, no. 26, pp. 3609-3611, Jun. 1995.

[10] J. P. Seif et al., "Strategies for doped nanocrystalline silicon integration in silicon heterojunction solar cells," IEEE J. Photovolt., vol. 6, no. 5, pp. 1132-1140, Sep. 2016.

[11] G. Nogayet al., "Nanocrystalline silicon carrier collectors for silicon heterojunction solar cells and impact on low-temperature device characteristics," IEEE J. Photovolt., vol. 6, no. 6, pp. 1654-1662, Nov. 2016

[12] A. N. Fioretti, M. Boccard, R. Monnard, and C. Ballif, "Low-temperature p-type microcrystalline silicon as carrier selective contact for silicon heterojunction solar cells," IEEE J. Photovolt., vol. 9, no. 5, pp. 1158-1165, Sep. 2019.

[13] M. Balestrieri et al., "Characterization and optimization of indium tin oxide films for heterojunction solar cells," Sol. Energy Mater. Sol. Cells, vol. 95 , no. 8, pp. 2390-2399, Aug. 2011.

[14] K.-U. Ritzau, T. Behrendt, D. Palaferri, M. Bivour, and M. Hermle, "Hydrogen doping of Indium Tin Oxide due to thermal treatment of hetero-junction solar cells," Thin Solid Films, vol. 599, no. Supplement C, pp. 161-165, Jan. 2016.

[15] B. Aïssa et al., "Impact of the oxygen content on the optoelectronic properties of the indium-tin-oxide based transparent electrodes for silicon heterojunction solar cells," AIP Conf. Proc., vol. 2147, no. 1, Aug. 2019, Art. no. 30001

[16] J. Haschke et al., "Annealing of silicon heterojunction solar cells: interplay of solar cell and indium tin oxide properties," IEEE J. Photovolt., vol. 9, no. 5, pp. 1202-1207, Sep. 2019.

[17] A. B. Morales-Vilches et al., "ITO-free silicon heterojunction solar cells with $\mathrm{ZnO}: \mathrm{Al} / \mathrm{SiO}_{2}$ front electrodes reaching a conversion efficiency of 23\%," IEEE J. Photovolt., vol. 9, no. 1, pp. 34-39, Jan. 2019.
[18] J.-P. Niemelä et al., "Rear-emitter silicon heterojunction solar cells with atomic layer deposited $\mathrm{ZnO}$ : $\mathrm{Al}$ serving as an alternative transparent conducting oxide to $\mathrm{In}_{2} \mathrm{O}_{3}: \mathrm{Sn}$," Sol. Energy Mater. Sol. Cells, vol. 200, Sep. 2019, Art. no. 109953.

[19] L. Senaud et al., "Aluminium-doped zinc oxide rear reflectors for highefficiency silicon heterojunction solar cells," IEEE J. Photovolt., vol. 9, no. 5, pp. 1217-1224, Sep. 2019.

[20] J. Haschke et al., "Injection-dependent lateral resistance in front-junction solar cells with nc-Si:H and a-Si:H hole selective contact," in Proc. 46th IEEE Photovolt. Specialists Conf., Jun. 2019.

[21] M. Klingsporn et al., "Resolving the nanostructure of plasma-enhanced chemical vapor deposited nanocrystalline $\mathrm{SiO}_{\mathrm{x}}$ layers for application in solar cells," J. Appl. Phys., vol. 119, no. 22, Jun. 2016, Art. no. 223104.

[22] P. P. Michałowski, W. Kaszub, A. Merkulov, and W. Strupiński, "Secondary ion mass spectroscopy depth profiling of hydrogen-intercalated graphene on SiC," Appl. Phys. Lett., vol. 109, no. 1, Jul. 2016, Art. no. 11904

[23] R. Muydinov et al., "Crystallisation phenomena of $\operatorname{In}_{2} \mathrm{O}_{3}: \mathrm{H}$ films," Materials, vol. 12, no. 2, Jan. 2019, Art. no. 266.

[24] D. Pysch, A. Mette, and S. W. Glunz, "A review and comparison of different methods to determine the series resistance of solar cells," Sol. Energy Mater. Sol. Cells, vol. 91, no. 18, pp. 1698-1706, Nov. 2007.

[25] V. Sittinger et al. "High power pulsed magnetron sputtering of transparent conducting oxides," Thin Solid Films, vol. 516, no. 17, pp. 5847-5859, Jul. 2008.

[26] M. Morales-Masis, S. De Wolf, R. Woods-Robinson, J. W. Ager, and C. Ballif, "Transparent electrodes for efficient optoelectronics," Adv. Electron. Mater., vol. 3, no. 5, p. 1600529, May 2017.

[27] S. Lany and A. Zunger, "Dopability, intrinsic conductivity, and nonstoichiometry of transparent conducting oxides," Phys. Rev. Lett., vol. 98, no. 4, Jan. 2007, Art. no. 45501.

[28] W.-F. Wu and B.-S. Chiou, "Effect of oxygen concentration in the sputtering ambient on the microstructure, electrical and optical properties of radio-frequency magnetron-sputtered indium tin oxide films," Semicond. Sci. Technol., vol. 11, no. 2, pp. 196-202, Feb. 1996.

[29] D. Mergel, "Thin films of ITO as transparent electrodes," Vak. Forsch Prax., vol. 18, no. S1, pp. 15-18, 2006.

[30] A. Cruz et al., "Effect of front TCO on the performance of rear-junction silicon heterojunction solar cells: Insights from simulations and experiments," Sol. Energy Mater. Sol. Cells, vol. 195, pp. 339-345, Jun. 2019.

[31] K. H. Kim, K. C. Park, and D. Y. Ma, "Structural, electrical and optical properties of aluminum doped zinc oxide films prepared by radio frequency magnetron sputtering," J. Appl. Phys., vol. 81, no. 12, pp. 7764-7772, Jun. 1997.

[32] S. Y. Herasimenka, W. J. Dauksher, M. Boccard, and S. Bowden, "ITO/SiO $\mathrm{x}: \mathrm{H}$ stacks for silicon heterojunction solar cells," Sol. Energy Mater. Sol. Cells, vol. 158, Part 1, pp. 98-101, Dec. 2016.

[33] T. Koida, H. Fujiwara, and M. Kondo, "High-mobility hydrogendoped transparent conductive oxide for a-Si:H/c-Si heterojunction solar cells," Sol. Energy Mater. Sol. Cells, vol. 93, no. 6-7, pp. 851-854, Jun. 2009.

[34] S. De Wolf and M. Kondo, "Boron-doped a-Si:H/c-Si interface passivation: Degradation mechanism," Appl. Phys. Lett., vol. 91, no. 11, Sep. 2007, Art. no. 112109 .

[35] D. C. Look et al., "Self-compensation in semiconductors: The Zn vacancy in Ga-doped ZnO," Phys. Rev. B, vol. 84, no. 11, Sep. 2011, Art. no. 115202.

[36] N. Preissler, O. Bierwagen, A. T. Ramu, and J. S. Speck, "Electrical transport, electrothermal transport, and effective electron mass in single-crystalline $\mathrm{In}_{2} \mathrm{O}_{3}$ films," Phys. Rev. B, vol. 88, no. 8, Aug. 2013, Art. no. 85305.

[37] K. Ellmer and R. Mientus, "Carrier transport in polycrystalline transparent conductive oxides: a comparative study of zinc oxide and indium oxide," Thin Solid Films, vol. 516, no. 14, pp. 4620-4627, May 2008

[38] C. Lohaus et al., "Enhancing electrical conductivity of room temperature deposited $\mathrm{Sn}$-doped $\operatorname{In}_{2} \mathrm{O}_{3}$ thin films by hematite seed layers," Appl. Phys. Lett., vol. 112, no. 15, Apr. 2018, Art. no. 152105.

[39] J. Y. W. Seto, "The electrical properties of polycrystalline silicon films," J. Appl. Phys., vol. 46, no. 12, pp. 5247-5254, Dec. 1975. 